\title{
Molecular cytogenetics and St-chromosome-specific molecular markers development of novel stripe rust resistant wheat-Thinopyrum intermedium as well as wheat-Thinopyrum ponticum substitution lines
}

\author{
Siwen Wang \\ Northwest A\&F University \\ Changyou Wang \\ Northwest A\&F University \\ Xianbo Feng \\ Northwest A\&F University \\ Jixin Zhao \\ Northwest A\&F University \\ Pingchuan Deng \\ Northwest A\&F University \\ Yajuan Wang \\ Northwest A\&F University \\ Hong Zhang \\ Northwest A\&F University \\ Xinlun Liu \\ Northwest A\&F University \\ Tingdong Li \\ Northwest A\&F University \\ Chunhuan Chen \\ Northwest A\&F University \\ Baotong Wang \\ Northwest A\&F University \\ Wanquan Ji ( $\sim$ jiwanquan2008@126.com) \\ Northwest A\&F University
}

\section{Research Article}

Keywords: Thinopyrum intermedium, Thinopyrum ponticum, substitution lines, stripe rust resistance, St-chromosome-specific molecular markers

Posted Date: September 17th, 2021

DOI: https://doi.org/10.21203/rs.3.rs-911109/v1

License: (c) (1) This work is licensed under a Creative Commons Attribution 4.0 International License. Read Full License

Version of Record: A version of this preprint was published at BMC Plant Biology on March 12th, 2022. See the published version at https://doi.org/10.1186/s12870-022-03496-x. 


\section{Abstract \\ Background}

Owing to the excellent resistance to abiotic and biotic stress, Thionpyrum intermedium $\left(2 n=6 x=42, \mathrm{JJJ} \mathrm{J}^{\mathrm{S} S \mathrm{StSt}}\right)$ and Thinopyrum ponticum ( $2 n=$ $10 x=70$ ) are both widely utilized in wheat germplasm innovation programs. Disomic substitution lines (DSLs) carrying one pair of alien chromosomes are valuable bridge materials for novel genes transmission, FISH karyotype construction and specific molecular marker development.

\section{Results}

Six wheat-Thinopyrum DSLs derived from crosses between Abbondanza nullisomic lines $(2 n=40)$ and two octoploid Trititrigia lines $(2 n=8 x=56)$, were characterized by a sequential fluorescence in situ hybridization (FISH)-genome in situ hybridization (GISH), a multicolor GISH (mc-GISH), and an analysis of wheat 15K SNP array combined with molecular marker selection. ES-9 (DS2St (2A)) and ES-10 (DS3St (3D)) are wheat- Th. ponticum DSLs, while ES-23 (DS2St (2A)), ES-24 (DS3St (3D)), ES-25(DS2St (2B)), and ES-26 (DS2St (2D)) are wheat- Th. intermedium DSLs. ES-9, ES-23, ES-25 and ES-26 conferred higher thousand-kernel weight and stripe rust resistance at adult stages, while ES-10 and ES-24 performed highly resistant to stripe rust at all stages. Furthermore, cytological analysis showed that the alien chromosomes (2St/3St) belonging to the same homoeologous group derived from different donors carried the same FISH karyotype and could normally form a bivalent. Based on specific-locus amplified fragment sequencing (SLAF-seq), two 2St-chromosome-specific markers (PTH-005 and PTH-013) and two 3St-chromosome-specific markers (PTH-113 and PTH-135) were developed.

\section{Conclusions}

The six wheat- Thinopyrum disomic substitution lines conferring stripe rust resistance will be used as bridging parents for valuable resistant genes transmission. And the utility of PTH-113 and PTH-135 in a BC1F2 population showed the newly developed markers could be useful tools for efficient identification of St chromosomes in a common wheat background.

\section{Background}

Intermediate wheatgrass (Thinopyrum intermedium Barkworth \& D.R. Dewey, JJJsJs StSt, $2 n=6 x=42$ ) and tall wheatgrass (Thinopyrum ponticum (Podp.) Barkworth \& D. R. Dewey, $2 n=10 x=70$ ) are important allopolyploids of Thinoprum species. Because of the desirable tolerance to biotic and abiotic stresses, both of them have been widely used in wheat chromosome engineering breeding for decades [1, 2]. According to previous studies, the chromosomal composition of Th. intermedium and Th. ponticum have not been fully characterized. In terms of Th. intermedium, the chromosomal composition is generally regarded as JJJs JsStSt [3] or $\mathrm{J}^{\mathrm{r}} \mathrm{J}^{\mathrm{r}} \mathrm{J}^{\mathrm{vs}} \mathrm{J}^{\mathrm{vs}} \mathrm{StSt}$ [4]. The subgenome $\mathrm{J}$ or $\mathrm{J}^{\mathrm{r}}$ is highly homologous with genome $\mathrm{J}$ (Th. bessarabicum, $\left.\mathrm{J}^{\mathrm{b}}, \mathrm{E}^{\mathrm{b}}\right) / \mathrm{E}$ (Th. elongatum, $\left.\mathrm{J}^{\mathrm{e}}, \mathrm{E}^{\mathrm{e}}\right)$ [5], and the main controversy has been whether the genome $\mathrm{V}$ originating from Dasypyrum villosum $(2 n=2 x=14, \mathrm{VV})$ was involved in the recombinant subgenome $\mathrm{J}^{\mathrm{s}}$ or not $[6,7]$. Additionally, it was convinced that Th. intermedium contained a set of St chromosomes which probably derived from diploid Pseudoroegneria spicata $(2 n=2 x=14$, StSt) [8-10]. However, it has been still unclear that whether Th. ponticum contains St chromosomes and if the St genome as well as the J/E genome were affected by recombination during the allopolyploidization process $[11,12]$.

Although there are aspects of Th. intermedium genome and Th. ponticum genome remain undiscovered, numerous partial amphiploid lines have been successfully developed during the past decades [13-18]. Octoploid Trititrigia with advantageous traits served as significant cytogenetic resources to develop alien introgression lines and be further applied to wheat breeding programs [19-23]. Generally, octoploid Trititrigia lines carry a synthetic genome inherited from Th. intermedium or Th. ponticum. Therefore, according to the defined genome compositions of partial amphiploids by molecular cytogenetic mothed, it is possible to understand the chromosomal compositions of Thinopyrum allopolyploids. TAF46 is an important wheat- Th. intermedium partial amphiploid with a common wheat Vilmorin 27 background, and the six disomic addition lines L1, L2, L3, L4, L5 with L7 were developed from TAF46 [24]. Subsequently, molecular cytogenetic identification of TAF46 as well as the derived six addition lines revealed that the genome composition of TAF46 was $14 \mathrm{~A}+14 \mathrm{~B}+14 \mathrm{D}+2(1 \mathrm{~J})+2(2 \mathrm{St})+2(3 \mathrm{~J})+2(4 \mathrm{St})+2(5 \mathrm{~J})+2(6 \mathrm{St})+2(7 \mathrm{~J})[25-27]$, which suggested that chromosomes of St genome contained in Th. intermedium could be stably inherited, and it is feasible to introduce the St chromosomes into common wheat background for wheat genetic improvement.

Stripe rust (Puccinia striiformis f.sp. tritici, Pst) is a recurrent damaging disease causes serious yields decrease of wheat annually [28, 29]. Development and transfer of novel resistant genes contained in wheat related wild species is one of the most efficient and environment-friendly solutions. According to previous studies, St chromosomes originating from Th. intermedium carry several new stripe rust resistance genes, which are potentially optimal genetic resources for wheat breeding. Except the named wheat- Th. intermedium disomic addition lines (DALs), L4 (DA4St) and L7 (DA6St), a DS1St (1D) with stripe rust resistance was produced [30]. Additionally, a DA3St [31] and a DA7St (Song et al. 2013) were 
characterized, both carrying stripe rust resistant gene(s). However, at present no wheat- Thinopyrum intermedium 2St disomic substitution lines with stripe rust resistance have been reported.

In the present study, four wheat- Th. intermedium disomic substitution lines, ES-22, ES-23, ES-25 and ES-26, were generated from crosses between Abbondanza nullisomic lines $(2 n=40)$ and Zhong4 (a wheat- Th. intermedium partial amphiploid with stripe rust, $2 n=8 x=56$ ) with consecutive self-crosses for several years. While two wheat- Th. ponticum disomic substitution lines, ES-9 and ES-10, were derived from Xiaoyan784 (a wheatTh. ponticum partial amphiploid with stripe rust, $2 n=8 x=56$ ). Molecular cytogenetic analysis was to determine and compare the genome composition of the six alien lines. In addition, stripe rust resistance and potential value of the morphological characteristics for wheat breeding was evaluated. Finally, St-chromosome-specific markers were developed and validated by specific-locus amplified fragment sequencing (SLAF-seq), which could be useful tools for efficient identification of St chromosomes in a common wheat background.

\section{Results}

\section{In situ hybridization of the six substitution lines}

By GISH analysis of somatic cells, alien chromosomes derived from Th. ponticum or Th. intermedium were able to be traced. It was showed that all the six alien lines, ES-9, ES-10, ES-23, ES-24, ES-25 and ES-26 contained 42 chromosomes (Fig. 1). ES-9 and ES-10 both carried two Th. ponticum chromosomes with a bright-green hybridization signal by using Th. ponticum genome DNA as a probe (Fig. 1, b1 and b2). Whereas ES-23 (Fig. 1, b3), ES-24 (Fig. 1, b4), ES-25 (Fig. 1, b5) and ES-26 (Fig. 1, b6), each of them carried two Th. intermedium chromosomes with a bright-green hybridization signal, by using the GISH probe of Th. intermedium. Therefore, ES-9 and ES-10 were wheat- Th. ponticum disomic substitution lines, and ES-23, ES-24, ES-25, as well as ES-26 were wheat- Th. intermedium disomic substitution lines.

Two Oligonucleotide probes of pTa535 and pSc119.2 were combined for a sequential FISH-GISH to simultaneously examine the elimination of wheat chromosomes in the six substitution lines. Comparisons of the FISH results between substitution lines and the corresponding parent lines, Abbondanza, Zhong4 and Xiaoyan784, were conducted. It was revealed that chromosome 2A was eliminated in ES-9 and substituted by one pair of Th. ponticum chromosomes with three specific signal bands, including the terminal pTa535 hybridization sites detected on short arms and long arms as well as an interstitial pTa535 signal on the long arms, which was different from the FISH patterns of other wheat chromosomes (Fig. 1, a1). ES-10 lost chromosome 3D and contained one pair of Th. ponticum chromosomes carrying terminal pSc119.2 hybridization sites on short arms with terminal pTa535 hybridization segments both on the long arms and short arms (Fig. 1, a2). Wheat chromosome 2A, chromosome 2B, as well as wheat chromosome 2D were eliminated in ES-23 (Fig. 1, a3), ES-25 (Fig. 1, a5) and ES-26 (Fig. 1, a6), respectively, and replaced by the same pair of Th. intermedium chromosomes with the identical FISH patterns detected in ES-9. Moreover, the telomeric region of chromosome 5B carrying a bright-green fluorescence signal was eliminated in ES-25 compared with other related materials. In terms of ES-24, chromosome 3D was substituted by a pair of Th. intermedium chromosomes with the FISH patterns almost consistent with the alien chromosomes detected in ES-10 (Fig. 1, a4).

According to the mc-GISH results, each of the six derived lines contained two alien chromosomes carrying a bright-red fluorescence signal originating from P. spicata (St) genome DNA (Fig. 1, c1-c6). It was shown that ES-9 and ES-10 carried two different pairs of St chromosomes derived from Th. ponticum. While ES-23, ES-25 and ES-26 contained the same pair of St chromosomes from Th. intermedium which was distinguished from the alien chromosomes of ES-24.

\section{Wheat 15K SNP array analysis of the six substitution lines}

The chromosomal composition of the six substitution lines were further determined based on genotype data by using a wheat 15K SNP array (Table S1). Generally, compared with Th. ponticum or Th. intermedium, the number of common SNP sequences detected between the substitution lines and Abbondanza was much higher. However, obvious point of intersection was found in each of the substitution lines (Fig. 2 a-f). As shown in ES-9 (Fig. 2a), an intersection point was distinctly observed in chromosome 2A, where ES-9 had the most of the same SNP marker loci as Th. ponticum but few SNP marker loci as Abbondanza. It suggested that chromosome 2A in ES-9 were replaced by the alien chromosomes of Th. ponticum, which was consistent with the FISH result. In ES-10 (Fig. 2b), the intersection point was detected in chromosome 3D where ES-10 had the most same SNP marker loci as Th. ponticum but few SNP marker loci compared with Abbondanza, which suggested that chromosome 3D of ES-10 were substituted by the pair of Th. ponticum chromosomes.

In terms of the wheat- Th. intermedicum alien lines, the intersection point was detected in chromosome 3D of ES-24, and the most same SNP marker loci was obtained from the comparison between Th. intermedium and ES-24. It was meant that chromosome 3D of ES-24 was replaced by the pair of Th. intermedium chromosomes (Fig. 2d). The intersection point of ES-23, ES-25 and ES-26 was undoubtedly identified in chromosome 2A (Fig. 2c), chromosome 2B (Fig. 2e), as well as chromosome 2D (Fig. 2f), respectively. Combined with the FISH results, it was revealed that chromosome 2A in ES-23, chromosome 2B in ES-25, as well as chromosome 2D in ES-26 were substituted by the same pair of Th. intermedium chromosomes. 


\section{PLUG marker analysis of the six substitution lines}

The 135 PLUG markers were screened to validated the homoeologous groups for the alien chromosomes. There were four PLUG markers (TNAC1142-Haell, TNAC1142-Taql, TNAC1132-Taql, TNAC1140-Taql) mapped to the second homoeologous group in ES-9, ES-23, ES-25 and ES-26 (Table S2; Fig. 3a-d). While three pairs of primers (TNAC1326-Haell, TNAC1326-Taql, TNAC1359-Taql) were distributed in the third homoeologous group in ES-10 and ES-24 (Table S7; Fig. 3e-g). Combined with the mc-GISH results of each substitution lines, it was showed that 2St-chromosomespecific bands could be amplified in ES-9, ES-23, ES-24, ES-25, ES-26, Th. intermedium and Th. ponticum. While 3St-chromosome-specific bands were identified in ES-10, ES-24, as well as, Th. intermedium and Th. ponticum. Whereas, the above polymorphic bands could not be amplified in Abbondanza.

Based on chromosomal composition analysis, the genome composition of ES-25 (Fig. 4d) was 14A + 12B + 14D + 2(2St), and ES-26 (Fig. 4f) was $14 A+14 B+12 D+2(2 S t)$. ES-23 and ES-9 were for the same genome composition of $12 A+14 B+14 D+2(2 S t)$, while ES-24 and ES-10 were for the same genome composition of 14A+14B+12D+2(3St). Remarkably, the alien chromosomes contained in ES-23 (Fig. 4b) and ES-24 (Fig. 4e) were derived from Th. intermedium, while the alien chromosomes carried by ES-9 (Fig. 4a) and ES-10 (Fig. 4c) were derived from Th. ponticum. Although the alien chromosomes belonging to the same homoeologous groups were derived from two different donors, identical FISH karyotypes of the alien chromosomes were respectively detected between ES-23 and ES-9 (2St), as well as ES-24 and ES-10 (3St).

\section{Evaluation of agricultural performance and resistance to stripe rust of the six substitution lines}

The agronomic traits of the six substitution lines as well as their parents Abbondanza and Xiaoyan784 (Table 1; Fig 5) or Zhong4 (Table 2; Fig 5) were compared. On average, the tiller number of ES-9 was higher and the spikes exhibited longer than Abbondanza. In terms of the other substitution lines derived from Zhong4, both ES-23 and ES-26 showed much more tillers, and the spikelets per spike number of ES-26 was higher than Abbondanza and Zhong4. Surprisingly, the average thousand-kernel weight of the alien lines containing chromosome 2St (ES-9, ES-23, ES-25 and ES-26) were more than $43 \mathrm{~g}$. It was indicated that the chromosome $2 \mathrm{St}$ whether originating from Th. ponticum or Th. intermedium increased thousand-kernel weight.

Table 1 Agronomic traits of the alien substitution lines ES-9, ES-10, as well as their parents (Abbondanza, Xiaoyan784)

\begin{tabular}{|llllllll|}
\hline Materials & $\begin{array}{l}\text { Plant height } \\
(\mathbf{c m})\end{array}$ & Tillers & $\begin{array}{l}\text { Spike length } \\
(\mathbf{c m})\end{array}$ & $\begin{array}{l}\text { Spikelets/ } \\
\text { spike }\end{array}$ & $\begin{array}{l}\text { Florets/ } \\
\text { spikelet }\end{array}$ & $\begin{array}{l}\text { Thousand Kenel Weight } \\
(\mathbf{g})\end{array}$ \\
\hline Xiaoyan784 & $112 \pm 6 \mathrm{a}$ & $11 \pm 3 \mathrm{~b}$ & $21 \pm 1.5 \mathrm{a}$ & $25 \pm 2 \mathrm{a}$ & $6 \pm 1 \mathrm{a}$ & $31 \pm 0.5 \mathrm{c}$ \\
\hline ES-9 & $105 \pm 5 \mathrm{a}$ & $25 \pm 4 \mathrm{a}$ & $13.9 \pm 1 \mathrm{~b}$ & $24 \pm 1 \mathrm{ab}$ & $4 \pm 1 \mathrm{~b}$ & $43 \pm 1 \mathrm{a}$ & awnless \\
\hline ES-10 & $90 \pm 5 \mathrm{~b}$ & $18 \pm 4 \mathrm{ab}$ & $14 \pm 1.5 \mathrm{~b}$ & $20 \pm 1 \mathrm{c}$ & $5 \pm 1 \mathrm{ab}$ & $36 \pm 1 \mathrm{~b}$ \\
\hline Abbondanza & $107 \pm 6 \mathrm{a}$ & $14 \pm 3 \mathrm{~b}$ & $14.4 \pm 1 \mathrm{~b}$ & $22 \pm 1 \mathrm{~b}$ & $4 \pm 1 \mathrm{~b}$ & $42 \pm 2 \mathrm{a}$ \\
\hline
\end{tabular}

Note: Different letters a, b and c indicate significant differences between ES-9, ES-10 and its wheat parent $(P<0.05)$

Table 2 Agronomic traits of the substitution lines ES-23, ES-24, ES-25, ES-26, as well as their parents (Abbondanza and Zhong4)

\begin{tabular}{|c|c|c|c|c|c|c|c|}
\hline Materials & $\begin{array}{l}\text { Plant height } \\
\text { (cm) }\end{array}$ & Tillers & $\begin{array}{l}\text { Spike length } \\
(\mathrm{cm})\end{array}$ & $\begin{array}{l}\text { Spikelets/ } \\
\text { spike }\end{array}$ & $\begin{array}{l}\text { Florets/ } \\
\text { spikelet }\end{array}$ & $\begin{array}{l}\text { Thousand Kenel Weight } \\
\text { (g) }\end{array}$ & Awnedness \\
\hline Zhong4 & $127 \pm 4 a$ & $12 \pm 3 b$ & $16 \pm 1.5 \mathrm{a}$ & $23 \pm 2 a b$ & $5 \pm 1 a$ & $31 \pm 0.5 c$ & Long awn \\
\hline ES-23 & $114 \pm 5 b$ & $23 \pm 4 a$ & $17 \pm 1.5 a$ & $21 \pm 2 b c$ & $4.4 \pm 1 a b$ & $43 \pm 1 a$ & awnless \\
\hline ES-24 & $87 \pm 6 c$ & $17 \pm 4 b$ & $11.6 \pm 1 c$ & $21 \pm 1 c$ & $4.4 \pm 1 a b$ & $37 \pm 2 b$ & Short awn \\
\hline ES-25 & $93 \pm 5 c$ & $15 \pm 4 b$ & $13 \pm 1.5 b$ & $23 \pm 1 b$ & $3.7 \pm 1 b$ & $45 \pm 1.5 a$ & Short awn \\
\hline ES-26 & $113 \pm 5 b$ & $27 \pm 4 a$ & $14 \pm 1.5 b$ & $25 \pm 1 a$ & $4.4 \pm 1 a b$ & $43 \pm 1.5 a$ & Short awn \\
\hline Abbondanza & $107 \pm 6 b$ & $14 \pm 3 b$ & $14.4 \pm 1 b$ & $22 \pm 1 b$ & $4 \pm 1 b$ & $42 \pm 2 a b$ & awnless \\
\hline
\end{tabular}

Note: Different letters a, b and c indicate significant differences between ES-23, ES-24, ES-25, ES-26 and its wheat parent $(P<0.05)$

At the adult stage, stripe rust reaction test of the six substitution lines was carried out with the susceptible control (HXH). Sequentially, the IT score of the six substitution lines, Abbondanza, Xiaoyan784, Zhong4, as well as Th. ponticum and Th. intermedium were recorded under field conditions. The IT score of the above-mentioned materials were as follows: Th. ponticum, IT = 0; Th. intermedium, IT = 0; Xiaoyan784, IT = 0; Zhong4, IT = 0; ES-9, IT = 1; ES-10, IT = 0; ES-23, IT = 1; ES-24, IT = 0; ES-25, IT = 1; ES-26, IT = 1; Abbondanza, IT = 3; HXH, IT = 4 (Fig 5c). Furthermore, the seedling 
stage stripe rust infection was conducted in the greenhouse, and the IT scores were recorded at 24 days post-inoculation (Fig $5 \mathrm{~d}$ ). With an IT score of 0, Zhong4 and Xiaoyan784 were immune to the disease. Additionally, ES-10 and ES-24 were nearly immune (IT score of 1). In contrast, Abbondanza, ES-9, ES-23, ES-25 and ES-26 were susceptible (IT score of 3). The results suggested that chromosome 2 St originating from Th. ponticum and Th. intermedium both conferred resistance to stripe rust at the adult stage, while chromosome 3St of Th. ponticum and Th. intermedium both carried remarkable resistance at whole stage.

\section{Meiotic chromosome pairing analysis of $\mathrm{F}_{1}$ hybrids}

Crosses were made between the alien lines with the same genome compositions. There were $15 \mathrm{~F}_{1}$ plants obtained from the cross between ES- 9 and ES-23, and $11 \mathrm{~F}_{1}$ plants obtained from the cross between ES-10 and ES-24. Meiotic chromosome pairing analysis of the $F_{1}$ hybrids was conducted to further validate the related genome constitution (Table 3). Mostly, the alien chromosomes derived from Th. intermedium and Th. ponticum but belonging to the same homoeologous group (2/3) could form a bivalent at metaphase l, and no trivalent or quadrivalent was observed at meiosis anaphase I. It was further revealed the close homoeologous relationship between the alien chromosomes derived from the two different donors.

Table 3 Chromosome pairing in the meiotic and meiotic phases for the hybrid $\mathrm{F}_{1}$ individuals

\begin{tabular}{|llllllll|}
\hline Material & No. of cells & Chromosome configuration & & & & \\
& & Univalent & Bivalent & & Trivalent & Quadrivalent \\
\hline ES-9×ES-23 & 144 & $0.47(0-2)$ & Rod & Ring & Total & & \\
ES-10×ES-24 & 135 & $0.39(0-2)$ & $2.69(1-4)$ & $17.93(17-21)$ & $20.62(20-21)$ & 0 & 0 \\
\hline
\end{tabular}

\section{Comparisons of genomic polymorphism analyses and St-chromosomes-specific molecular markers development}

After high-throughput sequencing, SLAF library was constructed with the sequencing details (Supplementary table 3). A total of 1,055,234 (ES-9), 938,861 (ES-10), 524,288 (ES-23), 1,026,271 (ES-24), 974,634 (Abbobdanza), 572,791 (Th. intermedium), and 513,056 (Th. ponticum) SLAFs were obtained. By bioinformatics analysis, 3203 (ES-9), 4455 (ES-23), 2775 (ES-10), and 3148 (ES-24) specific sequences were selected for further sequence alignments. There were 78 out of 263 sequences from ES-24 with homology more than $90 \%$ of ES-10 (78/153). In addition, 114 out of 221 sequences from ES-23 were more than 90\% homologous with ES-9 (114/177). To some degree, these results revealed the possible genomic similarity between the alien chromosomes of Th. intermedium and Th. ponticum.

According to the above sequence alignment results, 110 SLAFs from ES-23 regarded as 2St chromosome-specific fragments and 73 SLAFs from ES-24 regarded as 3St chromosome-specific fragments were selected. Subsequently, 183 pairs of primers were designed to amplify fragments from CS, Abbondanza, Zhong4, Xiaoyan784, ES-9, ES-23, ES-10, ES-24. In addition, specificity of the primers was further confirmed by analysis of Th. ponticum, Th. intermedium, tetraploid P. spicata, diploid P. spicata, Th. bessarabicum, Th. elongatum, and the wheat-Th. intermedium 1-7St addition line. Totally, two 2St-chromosome-specific molecular markers, PTH-005 and PTH-013, and two 3St-chromosome-specific molecular markers, PTH-113 and PTH-135, were developed (Fig 6, Table 4).

Table 4 Specific amplification markers of chromosome 2St and chromosome 3St.

\begin{tabular}{|c|c|c|c|}
\hline Specific primers & Primers $\left(5^{\prime}-3^{\prime}\right)$ & Amplified chromosomes & Annealing temperatures \\
\hline \multirow[t]{2}{*}{ PTH-005 } & F: TCCTCAACTGGAAACAAAGGA & \multirow[t]{2}{*}{$2 \mathrm{St}$} & \multirow[t]{2}{*}{56} \\
\hline & R: TTGGGAGTGAGTGTAGTTCAC & & \\
\hline \multirow[t]{2}{*}{ PTH-013 } & F: AGCCCTCCGGAAAGAATGAA & \multirow[t]{2}{*}{$2 S t$} & \multirow[t]{2}{*}{62} \\
\hline & R: CCGCTCAAACAATCGCTACC & & \\
\hline \multirow[t]{2}{*}{ PTH-113 } & F: AACAGGGTCAACGGGTTTGA & \multirow[t]{2}{*}{$3 S t$} & \multirow[t]{2}{*}{60} \\
\hline & R: TTGGTGCAGAAACAATGCGG & & \\
\hline \multirow[t]{2}{*}{ PTH-135 } & F: TGCCTCTAACACATGCATGT & \multirow[t]{2}{*}{$3 S t$} & \multirow[t]{2}{*}{60} \\
\hline & R: TCCAGTAGGTCTTGGCTCCA & & \\
\hline
\end{tabular}




\section{Utility of the 3 St-chromosome-specific markers in $\mathrm{BC}_{1} \mathrm{~F}_{2}$ population}

In order to validate that the stripe rust resistance gene(s) at whole stage were carried by chromosome $3 \mathrm{St}, 60 \mathrm{BC}_{1} \mathrm{~F}_{2}$ individuals of ES-24 and $\mathrm{HXH}$ were used for a genetic analysis. The evaluation of stripe rust resistance at the seedling stage revealed that Zhong4, ES-24, and the 33 $\mathrm{F}_{2}$ individuals were highly resistant to $P$ st race CYR32 (Fig 7a). Subsequently, 10 resistant $\mathrm{F}_{2}$ individuals as well as 10 susceptible ones were randomly selected for FISH analysis. Compared with the FISH karyotype of ES-24, chromosome 3St were detected in all the resistant individuals (Fig 7c) and susceptible ones had undetectable FISH pattern of chromosome 3St (Fig 7b). It was shown that the novel stripe rust resistant gene(s) originated from the alien chromosome 3 St of Th. intermedium.

Furthermore, the specificity of PTH-113 and PTH-135 was confirmed by PCR analyses of the $60 \mathrm{BC}_{1} \mathrm{~F}_{2}$ individuals (Fig 8). Combined with the result of seedling stage stripe rust resistance evaluation, Xiaoyan784, Zhong4, ES-9, ES-24, and the $33 \mathrm{BC}_{1} \mathrm{~F}_{2}$ plants conferring strong resistance to $P s t$ race CYR32 also carried 3St chromosome-specific markers. Oppositely, the other $26 \mathrm{BC}_{1} \mathrm{~F}_{2}$ plants, the parental line Abbondanza and susceptible control HXH, without specific amplification, were seriously susceptible to Pst race CYR32. Hence, the new developed chromosome-specific molecular markers could be used to rapidly trace the alien chromosome $3 \mathrm{St}$ in a common wheat background.

\section{Discussion}

On the basis of distant hybridization, chromosome manipulation has been widely utilized for wheat improvement programs, especially for breeding novel disease-resistant wheat lines. During the past few decades, numerous disease-resistant genes carried by wild related species have been successfully transferred to common wheat background by developing introgression lines [32-37]. Disomic substitution lines contained one pair of alien chromosomes with desirable resistant genes are vital bridge materials for small segments of introgression [38-40], which are valuable germplasm resources for wheat disease-resistant breeding. In the current study, six stable wheat-Thinopyrum derived lines were developed by nullisomic backcross method. Molecular cytogenetic analysis confirmed that ES-23 (DS2St (2A)), ES-24 (DS3St (3D)), ES-25 (DS2St (2B)) and ES26 (DS2St (2D)) are wheat- Th. intermedium disomic substitution lines, while ES-9 (DS2St (2A)) and ES-10 (DS3St (3D)) are wheat- Th. ponticum disomic substitution lines. It was shown that the four alien lines, ES-9, ES-23, ES-25 and ES-26 carrying chromosome 2St conferred higher thousand-kernel weight and stripe rust resistance at adult stages, while ES-10 and ES-24 both containing chromosome 3 St performed highly resistant to stripe rust at all stages. Therefore, all of the six substitution lines may be served as novel resistant germplasms for wheat breeding.

As one of the most commonly used technique, FISH analysis is generally used with GISH to discriminate characterize the alien chromosomes [41, 42] and to detect genomic changes in specific regions [43-45]. In this study, after characterized by sequential FISH-GISH and mc-GISH analysis, specific karyotype patterns of chromosome 2St and chromosome 3St derived from Th. intermedium and Th. ponticum were elucidated, which is significant for rapidly identifying the alien chromosomes in germplasm materials. Furthermore, chromosomal structure variation happened in ES-25 following the process of distant hybridization was detected by FISH. Compared with the parental lines, Abbondanza and Zhong4, telomere with subtelomeric region of chromosome 5BS carrying a blight pSc119.2 hybridization signal was eliminated in ES-25, which resulted a similar FISH pattern to chromosome $2 \mathrm{~B}$ of common wheat. For chromosome $2 \mathrm{~B}$ is almost metacentric whereas chromosome $5 \mathrm{~B}$ is absolutely submetacentric, it was clear that chromosome 2B were replaced by chromosome 2St of Th. intermedium (Fig $4 \mathrm{~h}$ ). Due to the dynamic and high frequent variable nature of subtelomeres of Triticeae species [46,47], it is difficult to access the possible function(s) of the deleted regions of chromosome 5BS. Because of no severe effects on viability of ES-25, the subtelomeric region elimination presumably contributed to genome diversity [48].

The genomic composition of Th. ponticum and Th. intermedium has been an interesting subject for a considerable time [49, 50]. During the past several decades, it was convinced that the set of St chromosomes contained in Th. intermedium were probably derived from $P$. spicata [51], whereas it has been still undefined that whether the St genome is one of the sets of chromosomes of Th. ponticum [11, 52]. According to molecular cytogenetic identification results, ES-23 and ES-9 (group 1) contained the same genome composition of $12 \mathrm{~A}+14 \mathrm{~B}+14 \mathrm{D}+2(2 \mathrm{St})$, while ES-24 and ES-10 (group 2) were for the same genome composition of 14A + 14B + 12D + 2(3St). Although the alien chromosomes derived from the two different donors, Th. intermedium and Th. ponticum, identical alien chromosome FISH patterns and similar specific agricultural performances were identified in each group of the plant materials. It was implied that St chromosomes were included in Th. ponticum, and could be stably inherited with remarkable genes. Furthermore, combined with the close homoeologous relationships between the alien chromosomes analyzed by meiotic chromosome pairing and genomic polymorphism, it was convinced that $P$. spicata representing the complete set of St chromosomes played an important role during the speciation of Th. ponticum, but the effects of the recombination events happened between diverse genomes through the allopolyploidization process need further analyses. All up, based on the specific SLAFs obtained in this study, it was feasible for us to develop transferable St-chromosome-specific molecular markers from Th. intermedium to Th. ponticum.

Although FISH-GISH analysis has been widely utilized to precisely characterized wheat- Th. intermedium lines for several decades, it is severely time-consuming. Specific molecular markers are able to rapidly trace the alien chromosome or even small segment introgression with the advantage traits for wheat improvement breeding programs. However, for the complete Th. intermedium genome has not been sequenced, there are only a few chromosome-specific markers enabled to be used [53-55]. With the development of sequencing technology, the first consensus genetic map of Th. intermedium was developed by genotyping-by-sequencing [56]. Subsequently, 635 [9] and 745 [57] unique Th. intermedium SNP 
markers have been successfully developed, totally including 225 St-chromosome-specific markers, with 27 of 2St-chromosome-specific markers and 25 of 3St-chromoosme-specific markers. Due to the much more complex genomic composition of Th. ponticum, the molecular markers development work was mainly focused on genome $E[52,58,59]$, especially in the following of the published complete genome of Th. elongatum [60]. In the present study, the wheat- Th. intermedium disomic substitution lines, ES-23(DS2St (2A)) and ES-24(DS3St (3D)) were sequenced by SLAF-seq for further St-chromosome-specific marker development. Two 2St-chromosome-specific molecular markers, PTH-005 and PTH-013, as well as two 3St-chromosome-specific molecular markers, $\mathrm{PTH}-113$ and $\mathrm{PTH}-135$ were obtained. FISH analysis of the $\mathrm{BC}_{1} \mathrm{~F}_{2}$ population of ES-24 and $\mathrm{HXH}$ combined with stripe rust resistance test (Fig 7) was to confirm that the stripe rust resistance gene(s) was derived from chromosome $3 \mathrm{St}$ of Th. intermedium. The utility of PTH-113 and PTH-135 amplification in the $\mathrm{BC}_{1} \mathrm{~F}_{2}$ individuals indicated that the St-chromosome-specific molecular markers enabled to serve as useful tools for tracing chromosome 3St of Th. intermedium in common wheat background. In addition, according to the close genetic relationship between the alien chromosomes of Th. ponticum and Th. intermedium analyzed in this study, the four St-chromosome-specific markers could be simultaneously amplified in Th. ponticum, tetraploid P. spicata, Th. intermedium and diploid $P$. spicata, as well as the corresponding substitution lines, ES-9, ES-23, ES-10 and ES-24. It suggested that the four St-chromosome-specific markers could also be utilized for rapidly detecting the St genome chromosomes of Th. ponticum. And the remarkable stripe rust resistance of ES-24 and ES-10 probably originated from the same gene(s), which need to be validated in future genetic analyses.

\section{Conclusions}

Four wheat- Th. intermedium and two wheat- Th. ponticum disomic substitution lines conferring stripe rust resistance were characterized and compared by molecular cytogenetic analysis, which will be used as bridging parents for valuable resistant genes transmission. Furthermore, according to the related homoeologous relationships, two 2St-chromosome-specific and two 3St-chromsome-specific molecular markers were developed by SLAF-seq for rapidly detecting the alien chromosomes of Th. intermedium and Th. ponticum in a common wheat background.

\section{Materials And Methods Plant materials}

The plant materials include Thinopyrum intermedium ( $\left.2 n=6 x=42, \mathrm{JJJ} \mathrm{J}^{\mathrm{s} S} \mathrm{SSt}\right)$, Thinopyrum ponticum $(2 n=10 x=70)$, diploid Pseudoroegneria spicata $(2 n=2 x=14$, StSt), tetraploid Pseudoroegneria spicata $(2 n=4 x=28$, StStStSt), Thinopyrum bessarabicum $(2 n=2 x=14, \mathrm{JJ})$, Thinopyrum elongatum $(2 n=2 x=14$, EE), wheat cv. Chinese Spring (CS), the Abbondanza lines, ES-9, ES-10, ES-23, ES-24, ES-25, ES-26, Zhong4 and Xiaoyan784, as well as two wheat- Th. intermedium disomic addition lines, L4 (DA4St) and L7 (DA6St). Twenty-six $F_{1}$ hybrids obtained from two cross combinations, ES-9 $\times$ ES-23 (15 plants), and ES-10 $\times$ ES-24 (11 plants). The $\mathrm{BC}_{1} \mathrm{~F}_{2}$ population comprising 60 individuals were derived from ES-24 and the wheat landrace Huixianhong $(\mathrm{HXH})$. Five wheat- Th. intermedium DALs were developed via hybridization between Abbondanza nullisomic lines and Zhong4, including DA1St, DA2St, DA3St, DA5St and DA7St (unpublished data). All the above-mentioned plant materials were preserved at the College of Agronomy, Northwest A\&F University, China. HXH was served as a susceptible control in the stripe rust resistance evaluation. The Pst races CYR32 were used for seedling stage of stripe rust resistance evaluation, as well as the CYR31 and CYR32 mixture were used for adult stage evaluation. All the Pst races were provided by the College of Plant Protection, Northwest A\&F University, China.

\section{In situ hybridization}

Chromosome spreads by drop method [14] were used for in situ hybridization analyses. The protocols of genomic DNA extracting, sequential FISH-GISH and mc-GISH were conducted by Wang et al. [41]. According to the nick translation method, total genomic DNA of Th. bessarabicum, Th. intermedium, as well as Th. ponticum was labeled with fluorescein-12-dUTP, while St genomic DNA from diploid and tetraploid $P$. spicata was labeled with Texas Red-5-Dutp, respectively, used as GISH and mc-GISH probes. And the sheared DNA of CS was as a blocking DNA. The Oligonucleotide probes combination of Oligo-pTa535 (red) and Oligo-pSc119.2 (green) were used for FISH analyses. Hybridization signals were observed and acquired under an Olympus BX53 fluorescence microscope.

\section{Wheat $15 \mathrm{~K}$ SNP array analysis}

Wheat 15K SNP genotyping arrays were used to genotype the 9 samples, including Abbondanza, ES-9, ES-10, ES-23, ES-24, ES-25, ES-26, Th. ponticum and Th. intermedium, by using Illumina SNP genotyping technology (China Golden Marker Biotechnology Company). There were 13199 SNP loci contained in the wheat 15K array and distributed on all 21 wheat chromosomes. Percentage of the same genotypes in each chromosome between two materials was obtained by calculating the rate of the same genotype loci number in total number of markers. The software Origin (OriginLab, USA) was used for data analysis and graphing.

\section{PLUG markers analysis}


The polymerase chain reaction (PCR)-based landmark unique gene (PLUG) markers (http://wheat.pw.usda.gov/SNP/new/pcr_primers.shtml) were selected for 21 wheat chromosomes among homoeologous groups 1 to 7 and then synthesized by AuGCT DNA-SYN Biotechnology Co. (Beijing, China). PCR assays and electrophoresis procedures were conducted as described [61].

\section{Agronomic traits and stripe rust resistance evaluation}

The stripe rust resistance evaluation was conducted in the field at the adult stage, while seedling stage test was conducted in the greenhouse. A mixture Pst races of CYR31 and CYR32 was used to evaluated the adult plant resistance of Abbondanza, ES-9, ES-10, ES-23, ES-24, ES-25, ES-26, Xiaoyan784 and Zhong4, with HXH severed as susceptible control. For further genetic analyses of the resistance, $P$ st races $\mathrm{CYR} 32$ was used to inoculate the above-mentioned materials at the seedling stage as well as the $\mathrm{BC}_{1} \mathrm{~F}_{2}$ population individuals of ES-24 and $\mathrm{HXH}$. The infection type (IT) was scored with a scale of 0-4 [62].

To assess the morphological traits, ten plants of each material (Abbondanza, ES-9, ES-10, ES-23, ES-24, ES-25, ES-26, Xiaoyan784 and Zhong4,) at physiology maturity stage were randomly selected during the 2019-2020 growing season. There were totally six agronomic traits recorded in the field which involved in plant height, spike length, number of spikelets per plant, number of tillers, number of spikelets per spike, awnedness, and thousand-kernel weight. The significant differences of each agronomic trait were analyzed by Duncan's multiple range test $(P<0.05)$.

\section{Meiotic chromosome pairing analysis of the $F_{1}$ hybrids}

Young spikes of $\mathrm{F}_{1}$ hybrids derived from the two crosses combinations (ES-9xES-23 and ES-10xES-24) at propriate stage were extracted at the suitable temperature under field conditions, and immediately treated with Carnoy's fixative fluid II (6:3:1 ethanol-chloroform-glacial acetic acid solution). Before cytological observation of pollen mother cells, anthers were extracted and stained with $1 \%$ acetocarmine. The chromosome configurations in the miosis period were observed, recorded and photographed.

\section{Genomic polymorphism analysis by pairwise comparisons}

On the basis of SLAF-seq [63], genomic DNA of Abbondanza, ES-9, ES-10, ES-23, ES-24, Th. intermedium and Th. ponticum was sequenced, carried out by Biomarker Technologies Co. (Beijing, China). The restriction endonuclease, Hae III was selected to digest the genomic DNA. According to the sequence similarity, the filtered SLAF pair-end reads (150 bp per read) were clustered. By using BLAST software, sequences with over $90 \%$ identity were divided into one SLAF locus. Genomic polymorphism analyses were conducted in two groups, ES-9 and ES-23 (group 1), as well as ES-10 and ES-24 (group 2). Firstly, all the SLAFs from the two groups were blasted with wheat genome, removing the sequences with high wheat homology (over 80\%). Secondly, the remaining SLAFs were further blasted with the sequences of Th. ponticum or Th. intermedium. Then the SLAFs with high identity (over 90\%) were remained, served as specific sequences of Th. ponticum attributing to ES-9 and ES-10, as well as the specific sequences of Th. intermedium attributing to ES-23 and ES-24. Finally, intercomparisons within groups were conducted and the specific SLAFs with high identity (over 90\%) were acquired.

\section{Development and validation of the St-chromosome-specific markers}

Based on the obtained specific SLAFs, PCR primers were designed for the amplification of the two groups of materials. All the primers were designed by using the online tool (Primer3 Plus, http://www.bioinformatics.nl/cgi-bin/primer3plus/primer3plus.cgi) and synthesized by AuGCT DNA-SYN Biotechnology Co. (Beijing, China). The amplified products were examined by using $2 \%$ agarose gel electrophoresis. The markers amplificated specific sequences in tetraploid $P$. spicata, diploid P. spicata, Th. ponticum, Th. intermedium, DA2St, ES-9 and ES-23, but not in CS, Abbondanza, Th. bessarabicum, Th. elongatum, the 1St and 3-7St addition lines, were served as 2St-chromosomes-specific molecular markers. While the markers presented in ES-10, ES-24, whereas absent in the 1-2St and 4-7St addition lines, were served as 3St-chromosomes-specific molecular markers. Subsequently, the 3St-chromosomes-specific markers were utilized in $\mathrm{BC}_{1} \mathrm{~F}_{2}$ individuals of ES-24 and $\mathrm{HXH}$ for a further genetic analysis.

The PCR amplifications were performed in a reaction of $20 \mu \mathrm{l}$, containing $1.6 \mu \mathrm{l}$ of template DNA (100ng/ $\mu \mathrm{l}), 1.6 \mu \mathrm{l} \mathrm{dNTP}$ mixture $(2.5 \mathrm{mM}$ each), $2 \mu \mathrm{l}$ of $10 \times$ PCR buffer ( $\mathrm{Mg}^{2+}$ plus), $1.4 \mu$ l of each primer $(10 \mu \mathrm{M}), 0.1 \mu$ rTaq DNA polymerase $(2.5 \mathrm{U} / \mu \mathrm{L}$, Takara) and $13.3 \mu \mathrm{L}$ double-distilled water. The PCR protocol was as follows: $94{ }^{\circ} \mathrm{C}$ for $4 \mathrm{~min} ; 32$ cycles of $94{ }^{\circ} \mathrm{C}$ for $30 \mathrm{~s}, 54-60{ }^{\circ} \mathrm{C}$ for $35 \mathrm{~s}, 72{ }^{\circ} \mathrm{C}$ for $30 \mathrm{~s}$, and $72{ }^{\circ} \mathrm{C}$ for $30 \mathrm{~s}$; $72{ }^{\circ} \mathrm{C}$ for $10 \mathrm{~min}$.

\section{Declarations}

\section{Acknowledgement}

We thank Prof. Baotong Wang, college of Plant Protection, Northwest A\&F University, Yangling, Shaanxi 712100, China, for providing the Pst races. 
Funding

This work was supported by the National Key Research and Development Program of China (grant No. 2016YFD0102001).

\section{Conflicts of interest}

It should be understood that none of the authors have any financial or scientific conflicts of interest with regard to the research described in this manuscript.

\section{Ethics approval}

We hereby confirm that this manuscript is our original work and has not been published nor has it been submitted simultaneously elsewhere.

\section{Consent to participate and consent for publication}

We further confirm that all authors have checked the manuscript and have agreed to the submission.

\section{Availability of data and material}

The datasets used or materials during the current study are available from the corresponding author on reasonable request.

\section{Code availability}

The codes during the current study are available from the corresponding author on reasonable request.

\section{Authors' contributions}

WJ and CW designed the project, SW performed the experiments and drafted the manuscript, JZ and PD provided help in analysis of wheat $15 \mathrm{~K}$ SNP array, XF, HZ and XL provided help in analyzing the morphological characters, YW, TL and CC provided help in preparing materials, BW provided the Pst races.

\section{References}

1. Chen Q, Conner RL, Li HJ, Sun SC, Ahmad F, Laroche A, Graf RJ: Molecular cytogenetic discrimination and reaction to wheat streak mosaic virus and the wheat curl mite in Zhong series of wheat-Thinopyrum intermedium partial amphiploids. Genome. 2003;46(1):135-145.

2. Li Z, Li B, Tong Y: The contribution of distant hybridization with decaploid Agropyron elongatum to wheat improvement in China. J Genet Genomics. 2008;35(8):451-456.

3. Chen Q, Conner RL, Laroche A, Thomas JB: Genome analysis of Thinopyrum intermedium and Thinopyrum ponticum using genomic in situ hybridization. Genome. 1998;41(4):580-586.

4. Wang RR, Larson SR, Jensen KB, Bushman BS, DeHaan LR, Wang S, Yan X: Genome evolution of intermediate wheatgrass as revealed by EST-SSR markers developed from its three progenitor diploid species. Genome. 2015;58(2):63-70.

5. Liu ZW, Wang RR: Genome analysis of Elytrigia caespitosa, Lophopyrum nodosum, Pseudoroegneria geniculata ssp. scythica, and Thinopyrum intermedium (Triticeae: Gramineae). Genome. 1993;36(1):102-111.

6. Wang RRC, Lu BR: Biosystematics and evolutionary relationships of perennial Triticeae species revealed by genomic analyses. J Syst Evol. 2014;52(6):697-705.

7. Deng CL, Bai LL, Fu SL, Yin WB, Zhang YX, Chen YH, Wang RRC, Zhang XQ, Han FP, Hu ZM: Microdissection and Chromosome Painting of the Alien Chromosome in an Addition Line of Wheat-Thinopyrum intermedium. Plos One. 2013;8(8).

8. Mahelka V, Kopecky D, Pastova L: On the genome constitution and evolution of intermediate wheatgrass (Thinopyrum intermedium: Poaceae, Triticeae). BMC Evol Biol. 2011;11:127.

9. Cseh A, Yang CY, Hubbart-Edwards S, Scholefield D, Ashling SS, Burridge AJ, Wilkinson PA, King IP, King J, Grewal S: Development and validation of an exome-based SNP marker set for identification of the St, J(r) and J(vs) genomes of Thinopyrym intermedium in a wheat background. Theor Appl Genet. 2019;132(5):1555-1570.

10. Li J, Yu Z, Zhang A, Yin Y, Tang L, Li G, Zhang P, Khan I, Dundas I, Yang Z: Physical mapping of chromosome 7J and a purple coleoptile gene from Thinopyrum intermedium in the common wheat background. Planta. 2021;253(1):22. 
11. Kruppa K, Molnár-Láng M: Simultaneous visualization of different genomes (J, JSt and St) in a Thinopyrum intermedium $x$ Thinopyrum ponticum synthetic hybrid (Poaceae) and in its parental species by multicolour genomic in situ hybridization (mcGISH). Comp Cytogenet. 2016;10(2):283-293.

12. He F, Xing PY, Bao YG, Ren MJ, Liu SB, Wang YH, Li XF, Wang HG: Chromosome Pairing in Hybrid Progeny between Triticum aestivum and Elytrigia elongata. Front Plant Sci. 2017;8.

13. Fedak G, Chen Q, Conner RL, Laroche A, Petroski R, Armstrong KW: Characterization of wheat-Thinopyrum partial amphiploids by meiotic analysis and genomic in situ hybridization. Genome. 2000;43(4):712-719.

14. Han FP, Liu B, Fedak G, Liu ZH: Genomic constitution and variation in five partial amphiploids of wheat-Thinopyrum intermedium as revealed by GISH, multicolor GISH and seed storage protein analysis. Theor Appl Genet. 2004;109(5):1070-1076.

15. Zheng Q, Lv ZL, Niu ZX, Li B, Li HW, Xu SS, Han FP, Li ZS: Molecular Cytogenetic Characterization and Stem Rust Resistance of Five WheatThinopyrum ponticum Partial Amphiploids. J Genet Genomics. 2014;41(11):591-599.

16. Kruppa K, Turkosi E, Mayer M, Toth V, Vida G, Szakacs E, Molnár-Láng M: McGISH identification and phenotypic description of leaf rust and yellow rust resistant partial amphiploids originating from a wheat x Thinopyrum synthetic hybrid cross. J Appl Genet. 2016;57(4):427-437.

17. Cui Y, Xing P, Qi X, Bao Y, Wang H, Wang RR, Li X: Characterization of chromosome constitution in three wheat - Thinopyrum intermedium amphiploids revealed frequent rearrangement of alien and wheat chromosomes. BMC Plant Biol. 2021;21(1):129.

18. Wang H, Cheng S, Shi Y, Zhang S, Yan W, Song W, Yang X, Song Q, Jang B, Qi X et al: Molecular cytogenetic characterization and fusarium head blight resistance of five wheat-Thinopyrum intermedium partial amphiploids. Mol Cytogenet. 2021;14(1):15.

19. Li HW, Zheng Q, Pretorius ZA, Li B, Tang DZ, Li ZS: Establishment and characterization of new wheat-Thinopyrum ponticum addition and translocation lines with resistance to Ug99 races. J Genet Genomics. 2016;43(9):573-575.

20. Li HW, Boshoff WHP, Pretorius ZA, Zheng Q, Li B, Li ZS: Establishment of wheat-Thinopyrum ponticum translocation lines with resistance to Puccinia graminis f. sp. tritici Ug99. J Genet Genomics. 2019;46(8):405-407.

21. Li JB, Chen QH, Zhang P, Lang T, Hoxha S, Li GR, Yang ZJ: Comparative FISH and molecular identification of new stripe rust resistant wheatThinopyrum intermedium ssp. trichophorum introgression lines. Crop J. 2019;7(6):819-829.

22. Zheng XW, Tang CG, Han R, Zhao JJ, Qiao L, Zhang SW, Qiao LY, Ge C, Zheng J, Liu C: Identification, Characterization, and Evaluation of Novel Stripe Rust-Resistant Wheat-Thinopyrum intermedium Chromosome Translocation Lines. Plant Dis. 2020;104(3):875-881.

23. Cui L, Ren Y, Bao Y, Nan H, Tang Z, Guo Q, Niu Y, Yan W, Sun Y, Li H: Assessment of resistance to cereal cyst nematode, stripe rust and powdery mildew in the wheat-Thinopyrum intermedium derivatives and their chromosome composition. Plant Dis. 2021.

24. Figueiras A, González-Jaén M, Benito C: Biochemical evidence of homoeology between Triticum aestivum and Agropyron intermedium chromosomes. Theor Appl Genet. 1986;72(6):826-832.

25. Friebe B, Mukai Y, Gill B, Cauderon Y: C-banding and in-situ hybridization analyses of Agropyron intermedium, a partial wheat x Ag. intermedium amphiploid, and six derived chromosome addition lines. Theor Appl Genet. 1992;84:899-905.

26. Chen Q, Conner RL, Laroche A, Ji WQ, Armstrong KC, Fedak G: Genomic in situ hybridization analysis of Thinopyrum chromatin in a wheat-

Th. intermedium partial amphiploid and six derived chromosome addition lines. Genome. 1999;42(6):1217-1223.

27. Forster BP, Reader SM, Forsyth SA, Koebner RMD, Miller TE, Gale MD, Cauderon Y: An assessment of the homoeology of six Agropyron intermedium chromosomes added to wheat. Genet Res. 2009;50(2):91-97.

28. Chen XM: Epidemiology and control of stripe rust [Puccinia striiformis $\mathrm{f}$. sp tritici] on wheat. Canadian Journal of Plant Pathology. 2005;27(3):314-337.

29. Kanwal M, Qureshi N, Gessese M, Forrest K, Babu P, Bariana H, Bansal U: An adult plant stripe rust resistance gene maps on chromosome 7A of Australian wheat cultivar Axe. Theor Appl Genet. 2021;134(7):2213-2220.

30. Hu L-J, Li G-R, Zeng Z-X, Chang Z-J, Liu C, Zhou J-P, Yang Z-J: Molecular cytogenetic identification of a new wheat-Thinopyrum substitution line with stripe rust resistance. Euphytica. 2010;177(2):169-177.

31. Nie L, Yang Y, Zhang J, Fu T: Disomic chromosome addition from Thinopyrum intermedium to bread wheat appears to confer stripe rust resistance. Euphytica. 2019;215(3).

Page $10 / 26$ 
32. Zhan HX, Li GR, Zhang XJ, Li X, Guo HJ, Gong WP, Jia JQ, Qiao LY, Ren YK, Yang ZJ et al: Chromosomal Location and Comparative Genomics Analysis of Powdery Mildew Resistance Gene Pm51 in a Putative Wheat-Thinopyrum ponticum Introgression Line. Plos One. 2014;9(11).

33. Ma PT, Xu HX, Han GH, Luo QL, Xu YF, Zhang XT, An DG, Li LH, Sun Y: Characterization of a Segregation Distortion Locus with Powdery Mildew Resistance in a Wheat-Thinopyrum intermedium Introgression Line WE99. Plant Dis. 2016;100(8):1541-1547.

34. Ceoloni C, Forte P, Kuzmanovic L, Tundo S, Moscetti I, De Vita P, Virili ME, D'Ovidio R: Cytogenetic mapping of a major locus for resistance to Fusarium head blight and crown rot of wheat on Thinopyrum elongatum 7EL and its pyramiding with valuable genes from a Th. ponticum homoeologous arm onto bread wheat 7DL. Theor Appl Genet. 2017;130(10):2005-2024.

35. Yang G, Boshoff WHP, Li H, Pretorius ZA, Luo Q, Li B, Li Z, Zheng Q: Chromosomal composition analysis and molecular marker development for the novel Ug99-resistant wheat-Thinopyrum ponticum translocation line WTT34. Theor Appl Genet. 2021.

36. Li H, Dong Z, Ma C, Xia Q, Tian X, Sehgal S, Koo D, Friebe B, Ma P, Liu W: A spontaneous wheat-Aegilops longissima translocation carrying Pm66 confers resistance to powdery mildew. Theor Appl Genet. 2020;133(4):1149-1159.

37. Li J, Dundas I, Dong C, Li G, Trethowan R, Yang Z, Hoxha S, Zhang P: Identification and characterization of a new stripe rust resistance gene Yr83 on rye chromosome 6R in wheat. Theor Appl Genet. 2020;133(4):1095-1107.

38. Guo J, Zhang XL, Hou YL, Cai JJ, Shen XR, Zhou TT, Xu HH, Ohm HW, Wang HW, Li AF et al: High-density mapping of the major FHB resistance gene Fhb7 derived from Thinopyrum ponticum and its pyramiding with Fhb1 by marker-assisted selection. Theor Appl Genet. $2015 ; 128(11): 2301-2316$.

39. Mago R, Zhang P, Xia XD, Zhang JP, Hoxha S, Lagudah E, Graner A, Dundas I: Transfer of stem rust resistance gene SrB from Thinopyrum ponticum into wheat and development of a closely linked PCR-based marker. Theor Appl Genet. 2019;132(2):371-382.

40. Fedak G, Chi D, Wolfe D, Ouellet T, Cao W, Han F, Xue A: Transfer of Fusarium Head Blight Resistance from Thinopyrum elongatum to bread wheat cultivar Chinese Spring. Genome. 2021.

41. Wang SW, Wang CY, Wang YZ, Wang YJ, Chen CH, Ji WQ: Molecular cytogenetic identification of two wheat-Thinopyrum ponticum substitution lines conferring stripe rust resistance. Mol Breed. 2019;39(11).

42. Wang YJ, Long DY, Wang YZ, Wang CY, Liu XL, Zhang H, Tian ZR, Chen CH, Ji WQ: Characterization and Evaluation of Resistance to Powdery Mildew of Wheat-Aegilops geniculata Roth 7M(g) (7A) Alien Disomic Substitution Line W16998. International Journal of Molecular Sciences. 2020;21(5).

43. Liu B, Xu C, Zhao N, Qi B, Kimatu JN, Pang J, Han F: Rapid genomic changes in polyploid wheat and related species: implications for genome evolution and genetic improvement. J Genet Genomics. 2009;36(9):519-528.

44. Li A-l, Geng S-f, Zhang L-q, Liu D-c, Mao L: Making the Bread: Insights from Newly Synthesized Allohexaploid Wheat. Molecular Plant. 2015;8(6):847-859.

45. Li G, Zhang T, Yu Z, Wang H, Yang E, Yang Z: An efficient Oligo-FISH painting system for revealing chromosome rearrangements and polyploidization in Triticeae. The Plant journal : for cell and molecular biology. 2021;105(4):978-993.

46. Zhang P, Li W, Fellers J, Friebe B, Gill BS: BAC-FISH in wheat identifies chromosome landmarks consisting of different types of transposable elements. Chromosoma. 2004;112(6):288-299.

47. Svacina R, Sourdille P, Kopecky D, Bartos J: Chromosome Pairing in Polyploid Grasses. Front Plant Sci. 2020;11:1056.

48. Oizumi Y, Kaji T, Tashiro S, Takeshita Y, Date Y, Kanoh J: Complete sequences of Schizosaccharomyces pombe subtelomeres reveal multiple patterns of genome variation. Nat Commun. 2021;12(1):611.

49. Wang RRC: Genome Relationships in the Perennial Triticeae Based on Diploid Hybrids and Beyond. Hereditas. 1992;116(1-2):133-136.

50. Tiryaki I, Karaoglu GB, Yucel G, Tuna M: Assessment of Thinopyrum ponticum (Podp.) Barkworth \& D. R. Dewey accessions using universal rice primers and molecular cytogenetics. Genet Resour Crop Evol. 2021.

51. Wang R, Li X, Robbins M, Larson S, Bushman S, Jones T, Thomas A: Pseudoroegneria spicataDNA sequence-based mapping and comparative genomics of the genome of (Pursh) Á. Löve versus wheat ( L.) and barley ( L.). Genome. 2020;63(9):445-457.

52. Baker L, Grewal S, Yang CY, Hubbart-Edwards S, Scholefield D, Ashling S, Burridge AJ, Przewieslik-Allen AM, Wilkinson PA, King IP et al: Exploiting the genome of Thinopyrum elongatum to expand the gene pool of hexaploid wheat. Theor Appl Genet. 2020;133(7):2213-2226.

Page $11 / 26$ 
53. Zhang Z, Xin Z, Larkin P: Molecular characterization of a Thinopyrum intermedium group 2 chromosome (2Ai-2) conferring resistance to barley yellow dwarf virus. Genome. 2001;44(6):1129-1135.

54. Hu L, Li G, Zhan H, Liu C, Yang Z: New St-chromosome-specific molecular markers for identifying wheat-Thinopyrum intermedium derivative lines. J Genet. 2012;91(2):e69-74.

55. Li G, Wang H, Lang T, Li J, La S, Yang E, Yang Z: New molecular markers and cytogenetic probes enable chromosome identification of wheat-Thinopyrum intermedium introgression lines for improving protein and gluten contents. Planta. 2016;244(4):865-876.

56. Kantarski T, Larson S, Zhang X, DeHaan L, Borevitz J, Anderson J, Poland J: Development of the first consensus genetic map of intermediate wheatgrass (Thinopyrum intermedium) using genotyping-by-sequencing. Theor Appl Genet. 2017;130(1):137-150.

57. Qiao L, Liu S, Li J, Li S, Yu Z, Liu C, Li X, Liu J, Ren Y, Zhang P et al: Thinopyrum intermediumDevelopment of Sequence-Tagged Site Marker Set for Identification of J, J, and St Sub-genomes of in Wheat Background. Frontiers in plant science. 2021;12:685216.

58. Hu LJ, Liu C, Zeng ZX, Li GR, Song XJ, Yang ZJ: Genomic rearrangement between wheat and Thinopyrum elongatum revealed by mapped functional molecular markers. Genes \& Genomics. 2012;34(1):67-75.

59. Li D, Zhang J, Liu H, Tan B, Zhu W, Xu L, Wang Y, Zeng J, Fan X, Sha L et al: Characterization of a wheat-tetraploid Thinopyrum elongatum 1E(1D) substitution line K17-841-1 by cytological and phenotypic analysis and developed molecular markers. BMC genomics. 2019;20(1):963.

60. Wang H, Sun S, Ge W, Zhao L, Hou B, Wang K, Lyu Z, Chen L, Xu S, Guo J et al: Fhb7Horizontal gene transfer of from fungus underlies head blight resistance in wheat. Science (New York, NY). 2020;368(6493).

61. Zhu C, Wang YZ, Chen CH, Wang CY, Zhang AC, Peng NN, Wang YJ, Zhang H, Liu XL, Ji WQ: Molecular cytogenetic identification of a wheat - Thinopyrum ponticum substitution line with stripe rust resistance. Genome. 2017;60(10):860-867.

62. Ma H, Singh RP, Mujeebkazi A: Suppression Expression of Resistance to Stripe Rust in Synthetic Hexaploid Wheat (Triticum-Turgidum X TTauschii). Euphytica. 1995;83(2):87-93.

63. Sun XW, Liu DY, Zhang XF, Li WB, Liu H, Hong WG, Jiang CB, Guan N, Ma CX, Zeng HP et al: SLAF-seq: An Efficient Method of Large-Scale De Novo SNP Discovery and Genotyping Using High-Throughput Sequencing. Plos One. 2013;8(3).

\section{Supplementary Tables}

Supplementary Table 1-1 Genotype data of wheat 15K SNP arrays 


\begin{tabular}{|c|c|c|c|c|c|c|c|c|}
\hline Chromosome & $\begin{array}{l}\text { No. of } \\
\text { markers }\end{array}$ & $\begin{array}{l}\text { No. of valid } \\
\text { markers in } \\
\text { Abbondanza }\end{array}$ & $\begin{array}{l}\text { No. of } \\
\text { valid } \\
\text { markers } \\
\text { in ES-9 }\end{array}$ & $\begin{array}{l}\text { No. of } \\
\text { valid } \\
\text { markers } \\
\text { in Th. } \\
\text { ponticum }\end{array}$ & $\begin{array}{l}\text { No. of same } \\
\text { markers } \\
\text { (Abbondanza } \\
\text { vs. ES-9) }\end{array}$ & $\begin{array}{l}\text { Percentage of } \\
\text { same markers } \\
\text { (Abbondanza } \\
\text { vs. ES-9) }\end{array}$ & $\begin{array}{l}\text { No. of same } \\
\text { markers (ES- } \\
9 \text { vs. Th. } \\
\text { ponticum) }\end{array}$ & $\begin{array}{l}\text { Percentage of } \\
\text { same markers } \\
\text { (ES-9 vs. Th. } \\
\text { ponticum) }\end{array}$ \\
\hline $1 \mathrm{~A}$ & 607 & 601 & 605 & 259 & 596 & $98.19 \%$ & 87 & $14.33 \%$ \\
\hline 1B & 670 & 661 & 659 & 303 & 641 & $95.67 \%$ & 131 & $19.55 \%$ \\
\hline 1D & 337 & 333 & 334 & 185 & 260 & $77.15 \%$ & 95 & $28.19 \%$ \\
\hline $2 A$ & 907 & 893 & 284 & 327 & 125 & $13.78 \%$ & 568 & $62.62 \%$ \\
\hline 2B & 736 & 728 & 716 & 377 & 547 & $74.32 \%$ & 142 & $19.29 \%$ \\
\hline 2D & 597 & 579 & 576 & 328 & 549 & $91.96 \%$ & 153 & $25.63 \%$ \\
\hline $3 A$ & 594 & 585 & 579 & 264 & 578 & $97.31 \%$ & 84 & $14.14 \%$ \\
\hline 3B & 997 & 986 & 985 & 391 & 973 & $97.59 \%$ & 141 & $14.14 \%$ \\
\hline 3D & 505 & 498 & 503 & 256 & 497 & $98.42 \%$ & 92 & $18.22 \%$ \\
\hline $4 \mathrm{~A}$ & 766 & 762 & 759 & 285 & 754 & $98.43 \%$ & 101 & $13.19 \%$ \\
\hline 4B & 589 & 584 & 580 & 230 & 564 & $95.76 \%$ & 96 & $16.30 \%$ \\
\hline 4D & 248 & 246 & 246 & 155 & 244 & $98.39 \%$ & 69 & $27.82 \%$ \\
\hline $5 A$ & 690 & 687 & 683 & 300 & 650 & $94.20 \%$ & 116 & $16.81 \%$ \\
\hline 5B & 763 & 755 & 756 & 355 & 714 & $93.58 \%$ & 130 & $17.04 \%$ \\
\hline 5D & 518 & 514 & 514 & 263 & 514 & $99.23 \%$ & 134 & $25.87 \%$ \\
\hline $6 A$ & 463 & 456 & 456 & 201 & 453 & $97.84 \%$ & 87 & $18.79 \%$ \\
\hline 6B & 768 & 754 & 753 & 336 & 749 & $97.53 \%$ & 133 & $17.32 \%$ \\
\hline 6D & 404 & 400 & 400 & 179 & 397 & $98.27 \%$ & 69 & $17.08 \%$ \\
\hline 7A & 735 & 729 & 728 & 329 & 679 & $92.38 \%$ & 115 & $15.65 \%$ \\
\hline 7B & 640 & 635 & 634 & 265 & 623 & $97.34 \%$ & 106 & $16.56 \%$ \\
\hline 7D & 665 & 659 & 659 & 328 & 649 & $97.59 \%$ & 108 & $16.24 \%$ \\
\hline Total & 13199 & 13045 & 12409 & 5916 & 11756 & $89.07 \%$ & 2757 & $20.89 \%$ \\
\hline
\end{tabular}

Supplementary Table 1-2 Genotype data of wheat 15K SNP arrays 


\begin{tabular}{|c|c|c|c|c|c|c|c|c|}
\hline Chromosome & $\begin{array}{l}\text { No. of } \\
\text { markers }\end{array}$ & $\begin{array}{l}\text { No. of valid } \\
\text { markers in } \\
\text { Abbondanza }\end{array}$ & $\begin{array}{l}\text { No. of } \\
\text { valid } \\
\text { markers } \\
\text { in ES- } \\
10\end{array}$ & $\begin{array}{l}\text { No. of } \\
\text { valid } \\
\text { markers } \\
\text { in Th. } \\
\text { ponticum }\end{array}$ & $\begin{array}{l}\text { No. of same } \\
\text { markers } \\
\text { (Abbondanza } \\
\text { vs. ES-10) }\end{array}$ & $\begin{array}{l}\text { Percentage of } \\
\text { same markers } \\
\text { (Abbondanza } \\
\text { vs. ES-10) }\end{array}$ & $\begin{array}{l}\text { No. of same } \\
\text { markers (ES- } \\
10 \text { vs. Th. } \\
\text { ponticum) }\end{array}$ & $\begin{array}{l}\text { Percentage of } \\
\text { same markers } \\
\text { (ES-10 vs. Th. } \\
\text { ponticum) }\end{array}$ \\
\hline $1 \mathrm{~A}$ & 607 & 601 & 603 & 259 & 522 & $86.00 \%$ & 93 & $15.32 \%$ \\
\hline 1B & 670 & 661 & 665 & 303 & 527 & $78.66 \%$ & 101 & $15.07 \%$ \\
\hline 1D & 337 & 333 & 334 & 185 & 261 & $77.45 \%$ & 96 & $28.49 \%$ \\
\hline $2 \mathrm{~A}$ & 907 & 893 & 849 & 327 & 682 & $75.19 \%$ & 158 & $17.42 \%$ \\
\hline 2B & 736 & 728 & 728 & 377 & 656 & $89.13 \%$ & 138 & $18.75 \%$ \\
\hline 2D & 597 & 579 & 577 & 328 & 527 & $88.27 \%$ & 148 & $24.79 \%$ \\
\hline $3 A$ & 594 & 585 & 582 & 264 & 382 & $64.31 \%$ & 99 & $16.67 \%$ \\
\hline 3B & 997 & 986 & 981 & 391 & 933 & $93.58 \%$ & 143 & $14.34 \%$ \\
\hline 3D & 505 & 498 & 159 & 256 & 62 & $12.28 \%$ & 262 & $51.88 \%$ \\
\hline $4 \mathrm{~A}$ & 766 & 762 & 759 & 285 & 468 & $61.10 \%$ & 91 & $11.88 \%$ \\
\hline 4B & 589 & 584 & 584 & 230 & 317 & $53.82 \%$ & 81 & $13.75 \%$ \\
\hline 4D & 248 & 246 & 245 & 155 & 228 & $91.94 \%$ & 67 & $27.02 \%$ \\
\hline $5 A$ & 690 & 687 & 685 & 300 & 619 & $89.71 \%$ & 116 & $16.81 \%$ \\
\hline 5B & 763 & 755 & 753 & 355 & 715 & $93.71 \%$ & 128 & $16.78 \%$ \\
\hline 5D & 518 & 514 & 517 & 263 & 354 & $68.34 \%$ & 106 & $20.46 \%$ \\
\hline $6 \mathrm{~A}$ & 463 & 456 & 457 & 201 & 406 & $87.69 \%$ & 85 & $18.36 \%$ \\
\hline $6 B$ & 768 & 754 & 754 & 336 & 615 & $80.08 \%$ & 134 & $17.45 \%$ \\
\hline 6D & 404 & 400 & 402 & 179 & 374 & $92.57 \%$ & 72 & $17.82 \%$ \\
\hline 7A & 735 & 729 & 728 & 329 & 538 & $73.20 \%$ & 113 & $15.37 \%$ \\
\hline 7B & 640 & 635 & 635 & 265 & 407 & $63.59 \%$ & 80 & $12.50 \%$ \\
\hline 7D & 665 & 659 & 660 & 328 & 545 & $81.95 \%$ & 129 & $19.40 \%$ \\
\hline Total & 13199 & 13045 & 12657 & 5916 & 10137 & $76.80 \%$ & 2440 & $18.49 \%$ \\
\hline
\end{tabular}

Supplementary Table 1-3 Genotype data of wheat 15K SNP arrays 


\begin{tabular}{|c|c|c|c|c|c|c|c|c|}
\hline Chromosome & $\begin{array}{l}\text { No. of } \\
\text { markers }\end{array}$ & $\begin{array}{l}\text { No. of valid } \\
\text { markers in } \\
\text { Abbondanza }\end{array}$ & $\begin{array}{l}\text { No. of } \\
\text { valid } \\
\text { markers } \\
\text { in ES- } \\
23\end{array}$ & $\begin{array}{l}\text { No. of valid } \\
\text { markers } \\
\text { in Th. } \\
\text { intermedium }\end{array}$ & $\begin{array}{l}\text { No. of same } \\
\text { markers } \\
\text { (Abbondanza } \\
\text { vs. ES-23) }\end{array}$ & $\begin{array}{l}\text { Percentage } \\
\text { of same } \\
\text { markers } \\
\text { (Abbondanza } \\
\text { vs. ES-23) }\end{array}$ & $\begin{array}{l}\text { No. of same } \\
\text { markers (ES- } \\
23 \text { vs. Th. } \\
\text { intermedium) }\end{array}$ & $\begin{array}{l}\text { Percentage } \\
\text { of same } \\
\text { markers (ES- } \\
23 \text { vs. Th. } \\
\text { intermedium) }\end{array}$ \\
\hline $1 \mathrm{~A}$ & 607 & 601 & 570 & 235 & 313 & $51.57 \%$ & 111 & $18.29 \%$ \\
\hline 1B & 670 & 661 & 622 & 294 & 367 & $54.78 \%$ & 128 & $19.10 \%$ \\
\hline 1D & 337 & 333 & 321 & 174 & 257 & $76.26 \%$ & 79 & $23.44 \%$ \\
\hline $2 \mathrm{~A}$ & 907 & 893 & 421 & 299 & 238 & $26.24 \%$ & 526 & $57.99 \%$ \\
\hline 2B & 736 & 728 & 712 & 343 & 650 & $88.32 \%$ & 134 & $18.21 \%$ \\
\hline 2D & 597 & 579 & 569 & 339 & 500 & $83.75 \%$ & 162 & $27.14 \%$ \\
\hline $3 A$ & 594 & 585 & 582 & 246 & 492 & $82.83 \%$ & 90 & $15.15 \%$ \\
\hline 3B & 997 & 986 & 970 & 379 & 892 & $89.47 \%$ & 156 & $15.65 \%$ \\
\hline 3D & 505 & 498 & 484 & 267 & 275 & $54.46 \%$ & 136 & $26.93 \%$ \\
\hline $4 \mathrm{~A}$ & 766 & 762 & 743 & 266 & 636 & $83.03 \%$ & 104 & $13.58 \%$ \\
\hline 4B & 589 & 584 & 550 & 219 & 322 & $54.67 \%$ & 97 & $16.47 \%$ \\
\hline 4D & 248 & 246 & 247 & 154 & 233 & $93.95 \%$ & 66 & $26.61 \%$ \\
\hline $5 A$ & 690 & 687 & 659 & 298 & 566 & $82.03 \%$ & 118 & $17.10 \%$ \\
\hline 5B & 763 & 755 & 741 & 335 & 690 & $90.43 \%$ & 117 & $15.33 \%$ \\
\hline 5D & 518 & 514 & 487 & 276 & 342 & $66.02 \%$ & 113 & $21.81 \%$ \\
\hline $6 \mathrm{~A}$ & 463 & 456 & 412 & 202 & 258 & $55.72 \%$ & 106 & $22.89 \%$ \\
\hline $6 B$ & 768 & 754 & 714 & 311 & 342 & $44.53 \%$ & 147 & $19.14 \%$ \\
\hline 6D & 404 & 400 & 384 & 192 & 259 & $64.11 \%$ & 105 & $25.99 \%$ \\
\hline 7A & 735 & 729 & 725 & 313 & 663 & $90.20 \%$ & 121 & $16.46 \%$ \\
\hline 7B & 640 & 635 & 619 & 261 & 542 & $84.69 \%$ & 100 & $15.63 \%$ \\
\hline 7D & 665 & 659 & 619 & 336 & 341 & $51.28 \%$ & 202 & $30.38 \%$ \\
\hline Total & 13199 & 13045 & 12151 & 5739 & 9169 & $69.47 \%$ & 2918 & $22.11 \%$ \\
\hline
\end{tabular}

Supplementary Table 1-4 Genotype data of wheat 15K SNP arrays 


\begin{tabular}{|c|c|c|c|c|c|c|c|c|}
\hline Chromosome & $\begin{array}{l}\text { No. of } \\
\text { markers }\end{array}$ & $\begin{array}{l}\text { No. of valid } \\
\text { markers in } \\
\text { Abbondanza }\end{array}$ & $\begin{array}{l}\text { No. of } \\
\text { valid } \\
\text { markers } \\
\text { in ES- } \\
24\end{array}$ & $\begin{array}{l}\text { No. of valid } \\
\text { markers } \\
\text { in Th. } \\
\text { intermedium }\end{array}$ & $\begin{array}{l}\text { No. of same } \\
\text { markers } \\
\text { (Abbondanza } \\
\text { vs. ES-24) }\end{array}$ & $\begin{array}{l}\text { Percentage } \\
\text { of same } \\
\text { markers } \\
\text { (Abbondanza } \\
\text { vs. ES-24) }\end{array}$ & $\begin{array}{l}\text { No. of same } \\
\text { markers (ES- } \\
24 \text { vs. Th. } \\
\text { intermedium) }\end{array}$ & $\begin{array}{l}\text { Percentage } \\
\text { of same } \\
\text { markers (ES- } \\
24 \text { vs. Th. } \\
\text { intermedium) }\end{array}$ \\
\hline $1 \mathrm{~A}$ & 607 & 601 & 603 & 235 & 580 & $95.55 \%$ & 88 & $14.50 \%$ \\
\hline 1B & 670 & 661 & 663 & 294 & 457 & $68.21 \%$ & 130 & $19.40 \%$ \\
\hline 1D & 337 & 333 & 331 & 174 & 287 & $85.16 \%$ & 89 & $26.41 \%$ \\
\hline $2 A$ & 907 & 893 & 890 & 299 & 882 & $97.24 \%$ & 137 & $15.10 \%$ \\
\hline 2B & 736 & 728 & 732 & 343 & 696 & $94.57 \%$ & 116 & $15.76 \%$ \\
\hline 2D & 597 & 579 & 588 & 339 & 571 & $95.64 \%$ & 165 & $27.64 \%$ \\
\hline $3 A$ & 594 & 585 & 584 & 246 & 544 & $91.58 \%$ & 86 & $14.48 \%$ \\
\hline 3B & 997 & 986 & 975 & 379 & 778 & $78.03 \%$ & 153 & $15.35 \%$ \\
\hline $3 D$ & 505 & 498 & 174 & 267 & 66 & $13.07 \%$ & 277 & $54.85 \%$ \\
\hline $4 \mathrm{~A}$ & 766 & 762 & 748 & 266 & 300 & $39.16 \%$ & 118 & $15.40 \%$ \\
\hline 4B & 589 & 584 & 582 & 219 & 567 & $96.26 \%$ & 105 & $17.83 \%$ \\
\hline 4D & 248 & 246 & 246 & 154 & 246 & $99.19 \%$ & 67 & $27.02 \%$ \\
\hline $5 A$ & 690 & 687 & 680 & 298 & 616 & $89.28 \%$ & 126 & $18.26 \%$ \\
\hline $5 B$ & 763 & 755 & 754 & 335 & 533 & $69.86 \%$ & 118 & $15.47 \%$ \\
\hline $5 D$ & 518 & 514 & 513 & 276 & 476 & $91.89 \%$ & 137 & $26.45 \%$ \\
\hline $6 A$ & 463 & 456 & 456 & 202 & 449 & $96.98 \%$ & 86 & $18.57 \%$ \\
\hline $6 B$ & 768 & 754 & 753 & 311 & 742 & $96.61 \%$ & 118 & $15.36 \%$ \\
\hline 6D & 404 & 400 & 400 & 192 & 395 & $97.77 \%$ & 85 & $21.04 \%$ \\
\hline $7 A$ & 735 & 729 & 726 & 313 & 633 & $86.12 \%$ & 123 & $16.73 \%$ \\
\hline 7B & 640 & 635 & 630 & 261 & 471 & $73.59 \%$ & 103 & $16.09 \%$ \\
\hline 7D & 665 & 659 & 665 & 336 & 332 & $49.92 \%$ & 195 & $29.32 \%$ \\
\hline Total & 13199 & 13045 & 12693 & 5739 & 10621 & $80.47 \%$ & 2622 & $19.87 \%$ \\
\hline
\end{tabular}

Supplementary Table 1-5 Genotype data of wheat 15K SNP arrays 


\begin{tabular}{|c|c|c|c|c|c|c|c|c|}
\hline Chromosome & $\begin{array}{l}\text { No. of } \\
\text { markers }\end{array}$ & $\begin{array}{l}\text { No. of valid } \\
\text { markers in } \\
\text { Abbondanza }\end{array}$ & $\begin{array}{l}\text { No. of } \\
\text { valid } \\
\text { markers } \\
\text { in ES- } \\
25\end{array}$ & $\begin{array}{l}\text { No. of valid } \\
\text { markers } \\
\text { in Th. } \\
\text { intermedium }\end{array}$ & $\begin{array}{l}\text { No. of same } \\
\text { markers } \\
\text { (Abbondanza } \\
\text { vs. ES-25) }\end{array}$ & $\begin{array}{l}\text { Percentage } \\
\text { of same } \\
\text { markers } \\
\text { (Abbondanza } \\
\text { vs. ES-25) }\end{array}$ & $\begin{array}{l}\text { No. of same } \\
\text { markers (ES- } \\
25 \text { vs. Th. } \\
\text { intermedium) }\end{array}$ & $\begin{array}{l}\text { Percentage } \\
\text { of same } \\
\text { markers (ES- } \\
25 \text { vs. Th. } \\
\text { intermedium) }\end{array}$ \\
\hline $1 \mathrm{~A}$ & 607 & 601 & 605 & 235 & 584 & $96.21 \%$ & 80 & $13.18 \%$ \\
\hline 1B & 670 & 661 & 662 & 294 & 638 & $95.22 \%$ & 125 & $18.66 \%$ \\
\hline 1D & 337 & 333 & 332 & 174 & 272 & $80.71 \%$ & 89 & $26.41 \%$ \\
\hline $2 \mathrm{~A}$ & 907 & 893 & 888 & 299 & 871 & $96.03 \%$ & 144 & $15.88 \%$ \\
\hline 2B & 736 & 728 & 251 & 343 & 102 & $13.86 \%$ & 454 & $61.68 \%$ \\
\hline 2D & 597 & 579 & 578 & 339 & 542 & $90.79 \%$ & 169 & $28.31 \%$ \\
\hline $3 A$ & 594 & 585 & 589 & 246 & 582 & $97.98 \%$ & 86 & $14.48 \%$ \\
\hline 3B & 997 & 986 & 984 & 379 & 975 & $97.79 \%$ & 153 & $15.35 \%$ \\
\hline 3D & 505 & 498 & 502 & 267 & 483 & $95.64 \%$ & 83 & $16.44 \%$ \\
\hline $4 \mathrm{~A}$ & 766 & 762 & 764 & 266 & 754 & $98.43 \%$ & 104 & $13.58 \%$ \\
\hline 4B & 589 & 584 & 583 & 219 & 558 & $94.74 \%$ & 104 & $17.66 \%$ \\
\hline 4D & 248 & 246 & 246 & 154 & 246 & $99.19 \%$ & 69 & $27.82 \%$ \\
\hline $5 A$ & 690 & 687 & 683 & 298 & 676 & $97.97 \%$ & 122 & $17.68 \%$ \\
\hline 5B & 763 & 755 & 671 & 335 & 580 & $76.02 \%$ & 159 & $20.84 \%$ \\
\hline 5D & 518 & 514 & 512 & 276 & 501 & $96.72 \%$ & 139 & $26.83 \%$ \\
\hline $6 A$ & 463 & 456 & 459 & 202 & 448 & $96.76 \%$ & 84 & $18.14 \%$ \\
\hline $6 B$ & 768 & 754 & 762 & 311 & 493 & $64.19 \%$ & 107 & $13.93 \%$ \\
\hline 6D & 404 & 400 & 402 & 192 & 387 & $95.79 \%$ & 84 & $20.79 \%$ \\
\hline 7A & 735 & 729 & 732 & 313 & 711 & $96.73 \%$ & 121 & $16.46 \%$ \\
\hline 7B & 640 & 635 & 622 & 261 & 405 & $63.28 \%$ & 105 & $16.41 \%$ \\
\hline 7D & 665 & 659 & 658 & 336 & 376 & $56.54 \%$ & 156 & $23.46 \%$ \\
\hline Total & 13199 & 13045 & 12485 & 5739 & 11184 & $84.73 \%$ & 2737 & $20.74 \%$ \\
\hline
\end{tabular}

Supplementary Table 1-6 Genotype data of wheat 15K SNP arrays 


\begin{tabular}{|c|c|c|c|c|c|c|c|c|}
\hline Chromosome & $\begin{array}{l}\text { No. of } \\
\text { markers }\end{array}$ & $\begin{array}{l}\text { No. of valid } \\
\text { markers in } \\
\text { Abbondanza }\end{array}$ & $\begin{array}{l}\text { No. of } \\
\text { valid } \\
\text { markers } \\
\text { in ES- } \\
26\end{array}$ & $\begin{array}{l}\text { No. of valid } \\
\text { markers } \\
\text { in Th. } \\
\text { intermedium }\end{array}$ & $\begin{array}{l}\text { No. of same } \\
\text { markers } \\
\text { (Abbondanza } \\
\text { vs. ES-26) }\end{array}$ & $\begin{array}{l}\text { Percentage } \\
\text { of same } \\
\text { markers } \\
\text { (Abbondanza } \\
\text { vs. ES-26) }\end{array}$ & $\begin{array}{l}\text { No. of same } \\
\text { markers (ES- } \\
26 \text { vs. Th. } \\
\text { intermedium) }\end{array}$ & $\begin{array}{l}\text { Percentage } \\
\text { of same } \\
\text { markers (ES- } \\
26 \text { vs. Th. } \\
\text { intermedium) }\end{array}$ \\
\hline $1 \mathrm{~A}$ & 607 & 601 & 604 & 235 & 592 & $97.53 \%$ & 82 & $13.51 \%$ \\
\hline 1B & 670 & 661 & 658 & 294 & 638 & $95.22 \%$ & 124 & $18.51 \%$ \\
\hline 1D & 337 & 333 & 332 & 174 & 328 & $97.33 \%$ & 90 & $26.71 \%$ \\
\hline $2 A$ & 907 & 893 & 886 & 299 & 863 & $95.15 \%$ & 141 & $15.55 \%$ \\
\hline 2B & 736 & 728 & 717 & 343 & 686 & $93.21 \%$ & 125 & $16.98 \%$ \\
\hline 2D & 597 & 579 & 236 & 339 & 114 & $19.10 \%$ & 321 & $53.77 \%$ \\
\hline $3 A$ & 594 & 585 & 572 & 246 & 503 & $84.68 \%$ & 86 & $14.48 \%$ \\
\hline 3B & 997 & 986 & 987 & 379 & 964 & $96.69 \%$ & 144 & $14.44 \%$ \\
\hline 3D & 505 & 498 & 500 & 267 & 233 & $46.14 \%$ & 161 & $31.88 \%$ \\
\hline $4 \mathrm{~A}$ & 766 & 762 & 763 & 266 & 746 & $97.39 \%$ & 100 & $13.05 \%$ \\
\hline 4B & 589 & 584 & 587 & 219 & 573 & $97.28 \%$ & 102 & $17.32 \%$ \\
\hline 4D & 248 & 246 & 246 & 154 & 229 & $92.34 \%$ & 65 & $26.21 \%$ \\
\hline $5 A$ & 690 & 687 & 686 & 298 & 663 & $96.09 \%$ & 123 & $17.83 \%$ \\
\hline 5B & 763 & 755 & 755 & 335 & 662 & $86.76 \%$ & 113 & $14.81 \%$ \\
\hline 5D & 518 & 514 & 506 & 276 & 457 & $88.22 \%$ & 129 & $24.90 \%$ \\
\hline $6 A$ & 463 & 456 & 460 & 202 & 214 & $46.22 \%$ & 60 & $12.96 \%$ \\
\hline 6B & 768 & 754 & 754 & 311 & 741 & $96.48 \%$ & 120 & $15.63 \%$ \\
\hline 6D & 404 & 400 & 400 & 192 & 185 & $45.79 \%$ & 72 & $17.82 \%$ \\
\hline 7A & 735 & 729 & 729 & 313 & 623 & $84.76 \%$ & 125 & $17.01 \%$ \\
\hline 7B & 640 & 635 & 634 & 261 & 306 & $47.81 \%$ & 93 & $14.53 \%$ \\
\hline 7D & 665 & 659 & 655 & 336 & 629 & $94.59 \%$ & 122 & $18.35 \%$ \\
\hline Total & 13199 & 13045 & 12667 & 5739 & 10949 & $82.95 \%$ & 2498 & $18.93 \%$ \\
\hline
\end{tabular}

Supplementary table 2 PLUG polymorphic markers mapped on homoeologous group 2 and 3 used to linkage analysis of Thinopyrum ponticum and Thinopyrum intermedium chromosome

\begin{tabular}{|c|c|c|c|c|c|}
\hline Markers & Type & Primers $\left(5^{\prime}-3^{\prime}\right)$ & Location & $\begin{array}{l}\text { Gel type/Restriction } \\
\text { enzyme }\end{array}$ & $\underset{(\mathrm{h})}{\operatorname{Tm}}\left({ }^{\circ} \mathrm{C}\right) /$ time of enzyme digesttion \\
\hline \multirow[t]{2}{*}{ TNAC1142 } & \multirow[t]{2}{*}{ PLUG } & F: GCCTACGAGTACATGGTCGAG & \multirow{2}{*}{$\begin{array}{l}2 \mathrm{AL} 2 \mathrm{BL} \\
2 \mathrm{DL}\end{array}$} & \multirow{2}{*}{$\begin{array}{l}1.5 \% \text { agarose } \\
\text { gel/ Taq®/Hael }\end{array}$} & \multirow[t]{2}{*}{$60 / 2$ or 3} \\
\hline & & R: CAGCATCCATAACCAGGATGT & & & \\
\hline \multirow[t]{2}{*}{ TNAC1132 } & \multirow[t]{2}{*}{ PLUG } & F: TATTGGTAGCCTTGTCGCTCT & \multirow{2}{*}{$\begin{array}{l}2 \mathrm{AL} 2 \mathrm{BL} \\
2 \mathrm{DL}\end{array}$} & \multirow[t]{2}{*}{$1.5 \%$ agarose gel/ Taq] } & \multirow[t]{2}{*}{$60 / 2$} \\
\hline & & R: TATGCTGCATGTGCTATCGAC & & & \\
\hline \multirow[t]{2}{*}{ TNAC1140 } & \multirow[t]{2}{*}{ PLUG } & F: TCCCAGAAATTACAAGGCTCA & \multirow{2}{*}{$\begin{array}{l}2 \mathrm{AL} 2 \mathrm{BL} \\
2 \mathrm{DL}\end{array}$} & \multirow[t]{2}{*}{$1.5 \%$ agarose gel/ Taq } & \multirow[t]{2}{*}{$60 / 2$} \\
\hline & & R: AGGAACCCTATGCATTGGAAA & & & \\
\hline \multirow[t]{2}{*}{ TNAC1326 } & \multirow[t]{2}{*}{ PLUG } & $\begin{array}{l}\text { F: } \\
\text { ACAGATCGAGATGTTTATTGAAA }\end{array}$ & \multirow[t]{2}{*}{$\begin{array}{l}\text { 3AS 3BS } \\
\text { 3DS }\end{array}$} & \multirow[t]{2}{*}{$\begin{array}{l}1.5 \% \text { agarose } \\
\text { gel/ Taq } ₫ / \text { Hae } \square\end{array}$} & \multirow[t]{2}{*}{$60 / 2$ or 3} \\
\hline & & R: GATCAAAGAGATGCGCTGAAG & & & \\
\hline \multirow[t]{2}{*}{ TNAC1359 } & \multirow[t]{2}{*}{ PLUG } & F: GTAAATAGCGCCATCTGCGTA & \multirow{2}{*}{$\begin{array}{l}\text { 3AL 3BL } \\
3 \mathrm{DL}\end{array}$} & \multirow[t]{2}{*}{$1.5 \%$ agarose gel/ Taq] } & \multirow[t]{2}{*}{$60 / 2$} \\
\hline & & R: CTCTGGATGCAGTTGGAATGT & & & \\
\hline
\end{tabular}


Supplementary table 3 Quality of SLAF data

\begin{tabular}{llllll} 
Genotype & Clean base (bp) & Clean reads & Q20(\%) & Q30(\%) & GC(\%) \\
\hline & & & & & \\
\hline ES-9 & $1,277,894,774$ & $6,401,833$ & 97.16 & 91.82 & 47.77 \\
\hline ES-10 & $1,054,658,932$ & $5,284,631$ & 96.36 & 90.29 & 47.83 \\
\hline ES-23 & $1,906,494,968$ & $9,555,684$ & 97.06 & 91.55 & 47.76 \\
\hline ES-24 & $1,228,787,742$ & $6,155,836$ & 97.08 & 91.59 & 47.72 \\
\hline Abbondanza & $1,297,710,674$ & $6,495,947$ & 96.31 & 90.13 & 47.65 \\
\hline Thinopyrum ponticum & $1,520,267,864$ & $7,613,789$ & 96.84 & 90.98 & 47.45 \\
\hline Thinopyrum intermedium & $2,038,483,374$ & $10,205,879$ & 97.10 & 91.50 & 46.77 \\
\hline
\end{tabular}

\section{Figures}

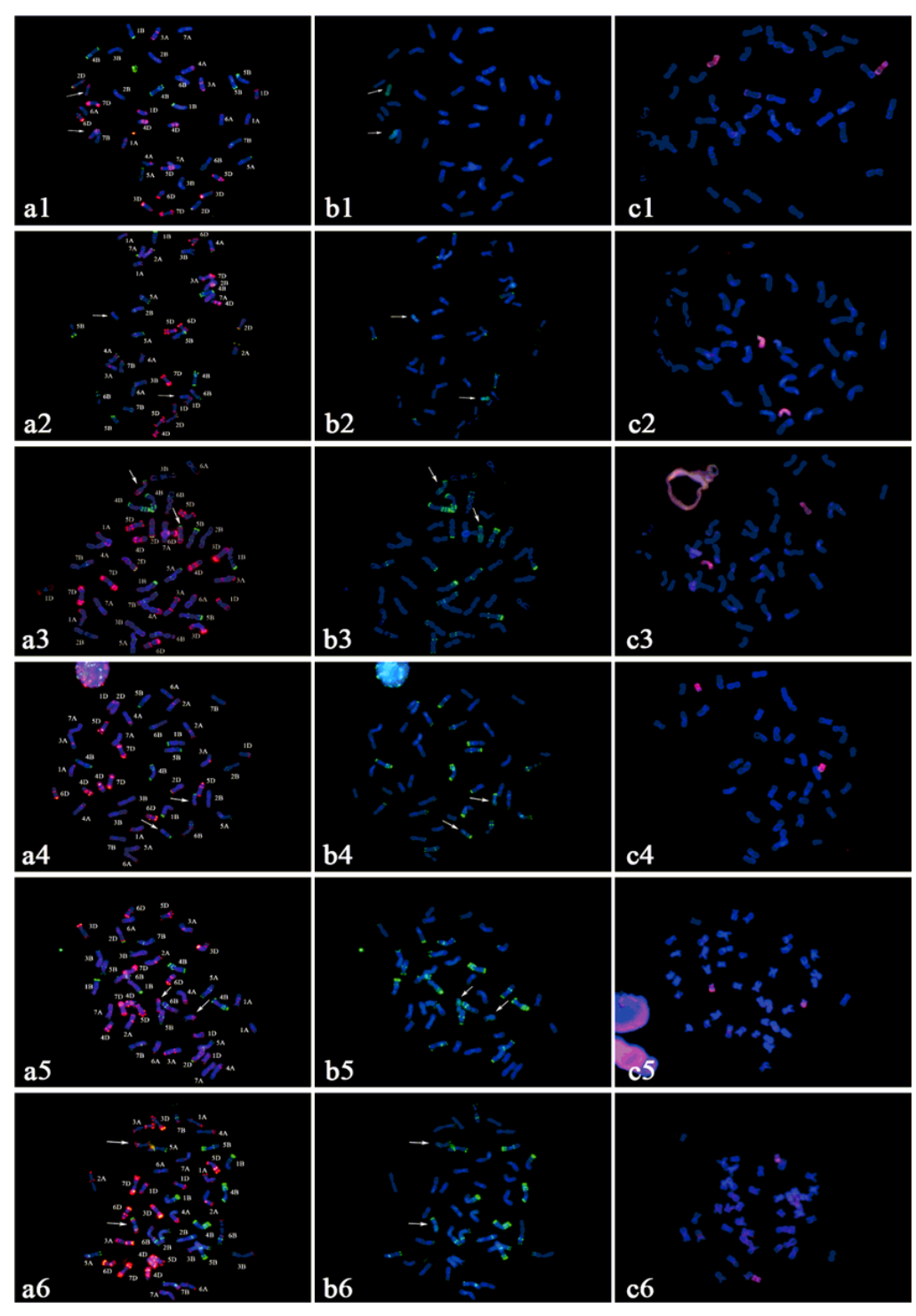

Figure 1 
In situ hybridization patterns of the six alien substitution lines. a FISH patterns of ES-9 (a1), ES-10 (a2), ES-23 (a3), ES-24 (a4), ES-25 (a5) and ES26 (a6): Oligo-pSc119.2 (green) and Oligo-pTa535 (red) as probes. b GISH patterns of ES-9 (b1) and ES-10 (b2): Thinopyrum ponticum genomic DNA (green) as probe and CS genomic DNA as a blocker; GISH patterns of ES-23 (b3), ES-24 (b4), ES-25 (b5) and ES-26 (b6): Thinopyrum intermedium genomic DNA (green) as probe and CS genomic DNA as a blocker. c Mc-GISH patterns of ES-9 (c1), ES-10 (c2): Thinopyrum bessarabicum (J) genomic DNA (green) and tetraploid Pseudoroegneria spicata (St) genomic DNA (red) as probes, CS genomic DNA as a blocker; ES-23 (c3), ES-24 (c4), ES-25 (c5) and ES-26 (c6): Th. bessarabicum (J) genomic DNA (green) and diploid P. spicata (St) genomic DNA (red) as probes, CS genomic DNA as a blocker. The arrows indicate the alien chromosomes of the six substitution lines.
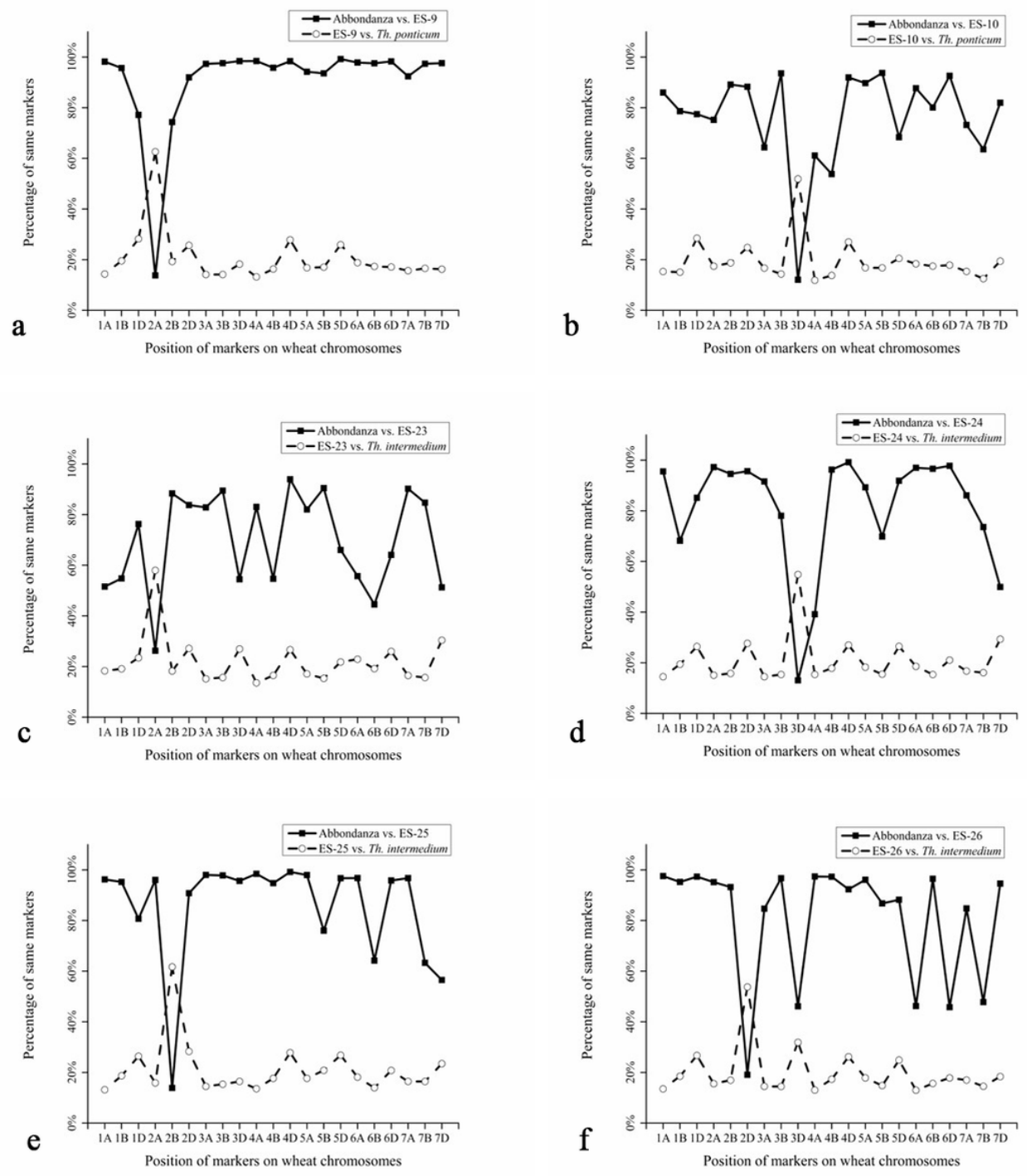

\section{Figure 2}

Wheat 15K SNP array analysis of the six alien substitution lines. a Wheat 15K SNP array analysis of ES-9. Obvious crossing point were detected in terms of the position of chromosome 2A. b Wheat 15K SNP array analysis of ES-10. Obvious crossing point were detected in terms of the position of chromosome 3D. c Wheat 15K SNP array analysis of ES-23. Obvious crossing point were detected in terms of the position of chromosome 2A. d Wheat 15K SNP array analysis of ES-24. Obvious crossing point were detected in terms of the position of chromosome 3D. e Wheat 15K SNP array analysis of ES-25. Obvious crossing point were detected in terms of the position of chromosome 2B. $f$ Wheat $15 \mathrm{~K}$ SNP array analysis of ES-26.

Obvious crossing point were detected in terms of the position of chromosome 2D. 

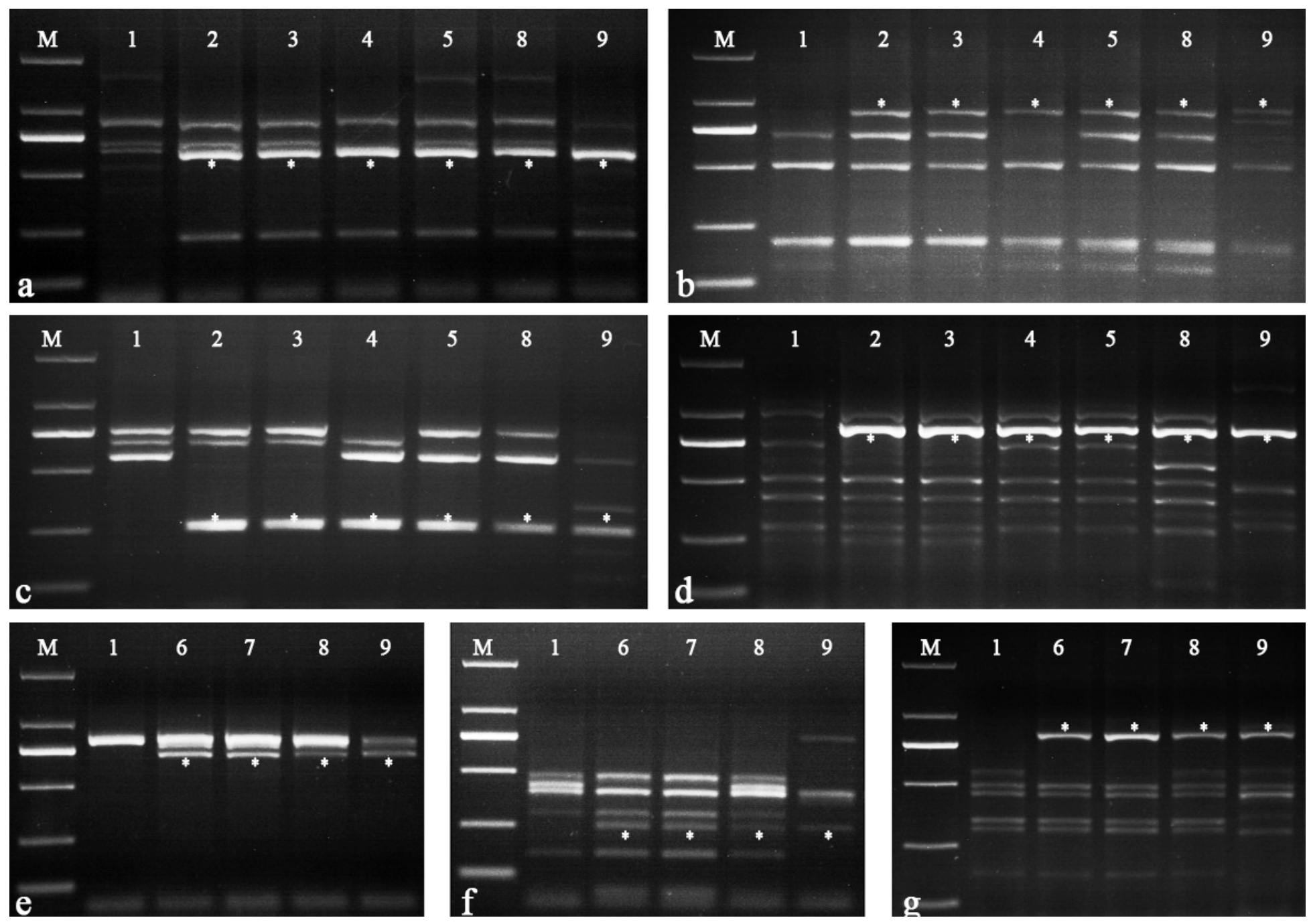

Figure 3

PLUG markers analysis of Abbondanza, the six alien substitution lines, Thinopyrum intermedium and Thinopyrum ponticum. a TNAC1142-Hae邓; b

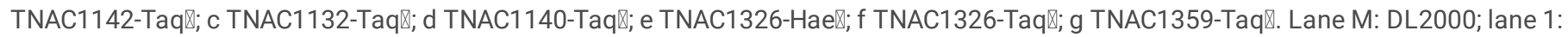

Abbondanza; lane 2: ES-9; lane 3: ES-23; lane 4: ES-25; lane 5: ES-26; lane 6: ES-10; lane 7: ES-24; lane 8: Th. intermedium; lane 9: Th. ponticum. The * indicates specific band of Th. ponticum and Th. intermedium. 

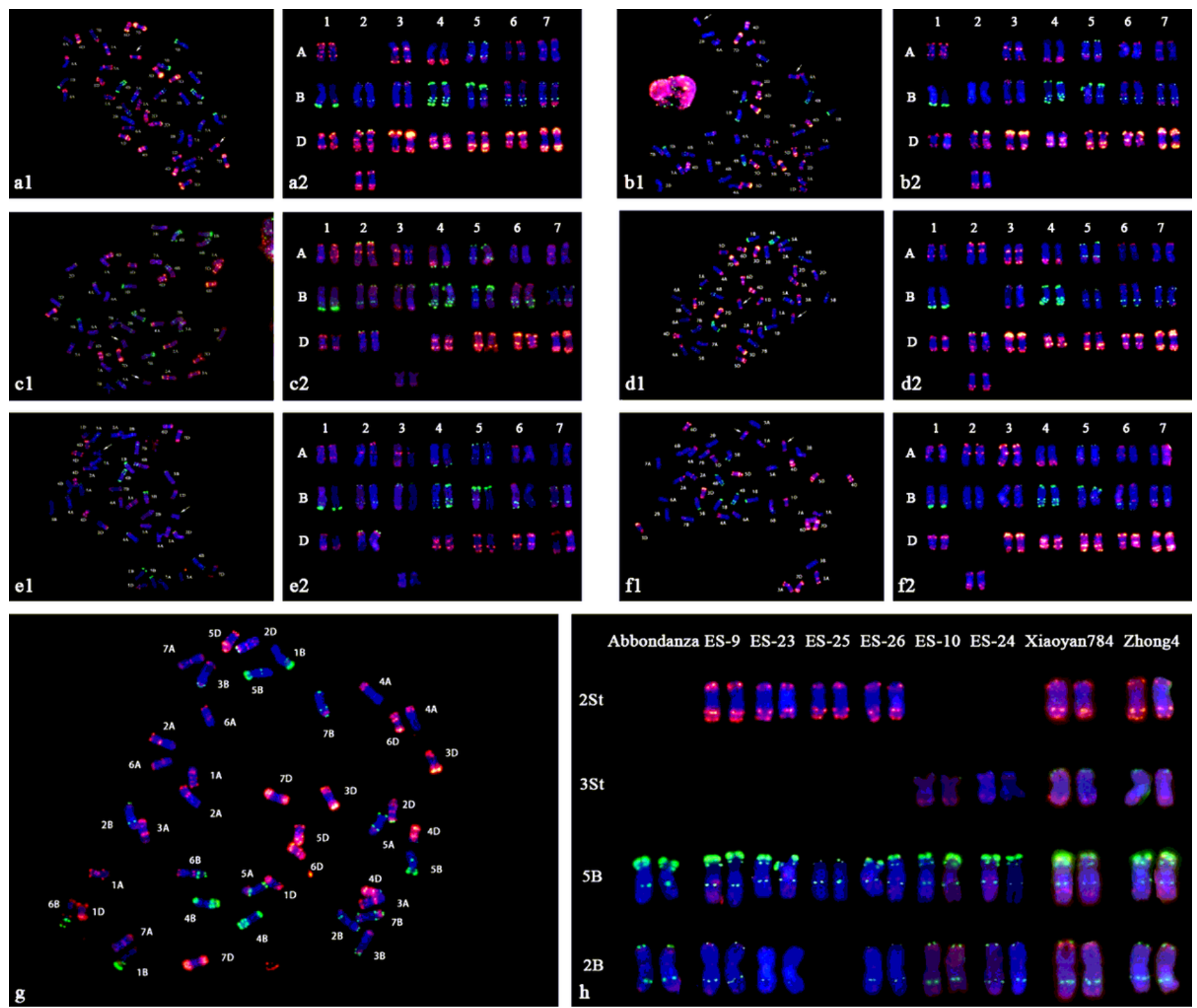

Abbondanza ES-9 ES-23 ES-25 ES-26 ES-10 ES-24 Xiaoyan784 Zhong4
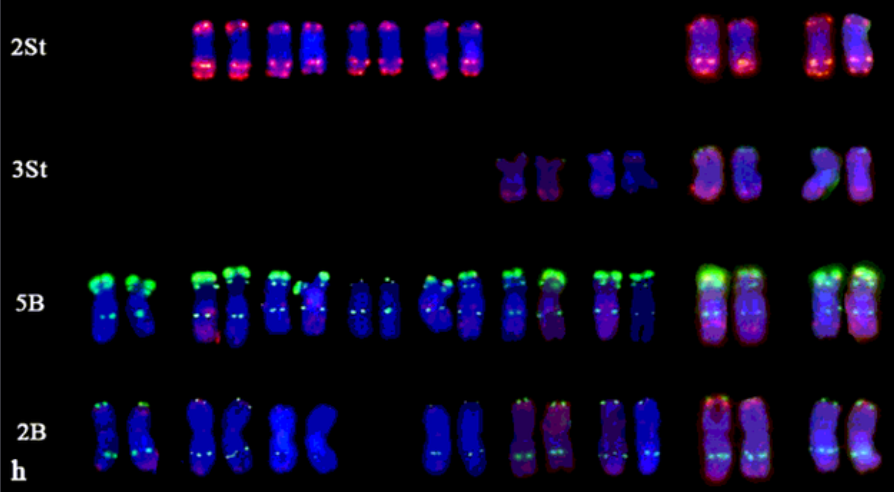

$3 \mathrm{St}$

2St

Figure 4

Karyotypes of the six alien substitution lines with the genomic composition variations. a Karyotype analysis of ES-9. Wheat chromosome $2 \mathrm{~A}$ were replaced by Thinopyrum ponticum chromosome 2St. b Karyotype analysis of ES-23. Wheat chromosomes $2 \mathrm{~A}$ were replaced by Thinopyrum intermedium chromosome 2St. c Karyotype analysis of ES-10. Wheat chromosome 3D were replaced by Th. ponticum chromosome 3St. d Karyotype analysis of ES-25. Wheat chromosome 2B were replaced by Th. intermedium chromosome 2St. e Karyotype analysis of ES-24. Wheat chromosome 3D were replaced by Th. intermedium chromosome 3St. f Karyotype analysis of ES-26. Wheat chromosome 2D were replaced by Th. intermedium chromosome 2St. g FISH analysis of Abbondanza. h FISH pattern comparisons of chromosome 2St, chromosome 3St, chromosome $5 \mathrm{~B}$ and chromosome $2 \mathrm{~B}$ between the six alien substitution lines and their parent lines Abbondanza, Xiaoyan784, and Zhong4. The telomeric region of chromosome 5BS carrying a bright-green fluorescence signal was eliminated in ES-25. Chromosome 2B are metacentric in all the abovementioned materials except ES-25. 


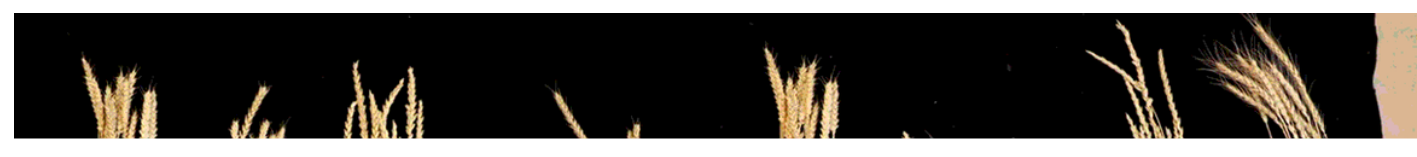

\section{Figure 5}

Evaluation of agronomic traits and stripe rust resistance. a Adult plants; b seeds; c symptoms in response to inoculation with the mixture of Pst races at the adult stage; d seedling stage reactions to Pst races CYR32. (1) Huixianhong; (2) Abbondanza; (3) ES-9; (4) ES-23; (5) ES-25; (6) ES-26; (7) ES-10; (8) ES-24; (9) Xiaoyan784; (10) Zhong4; (11) Thinopyrum ponticum; (12) Thinopyrum intermedium. 

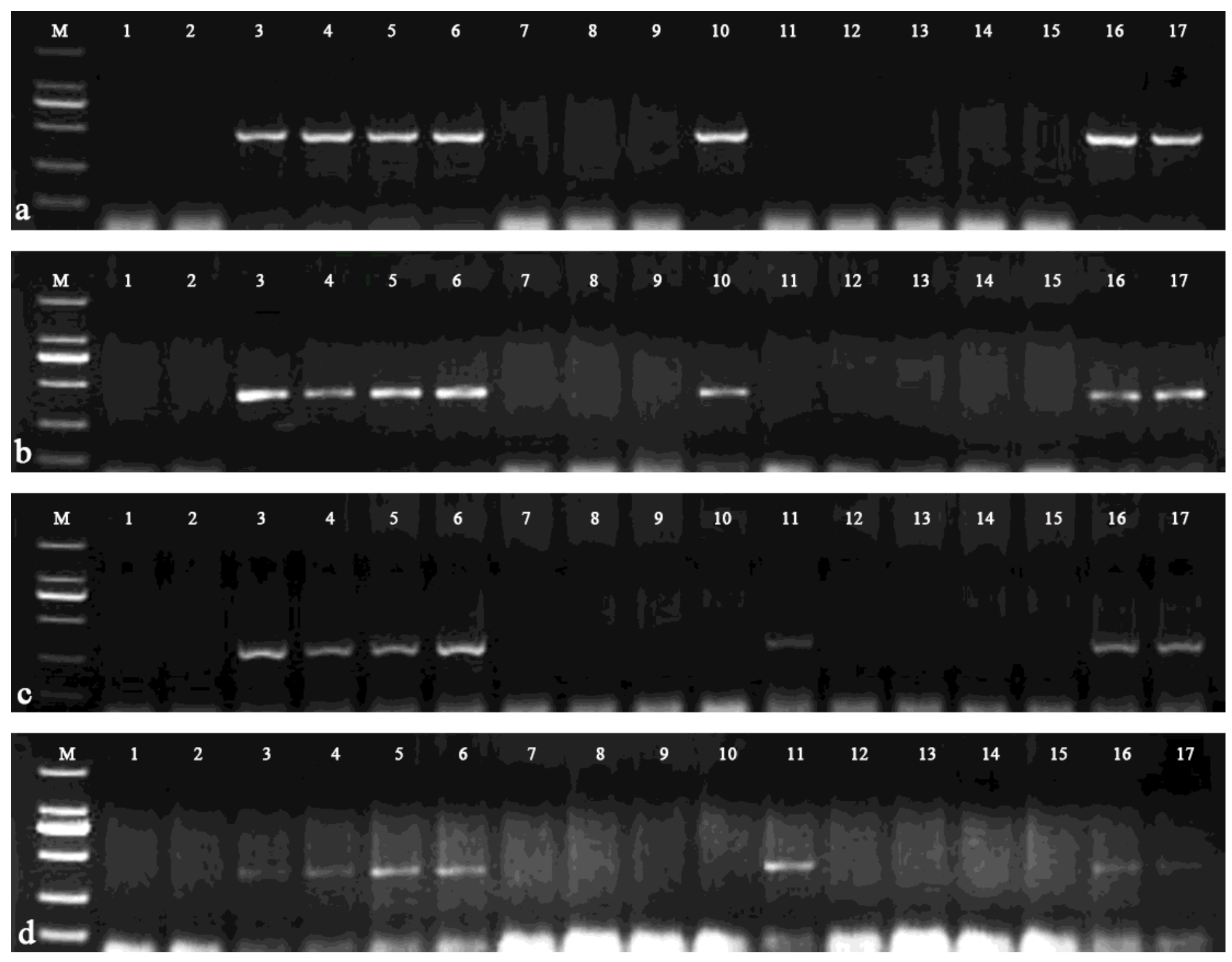

\section{Figure 6}

Specific amplification markers of chromosome 2St ( $a$ and $b$ ) and chromosome 3St (c and d). a PTH-005; b PTH-013; c PTH-113; d PTH-135. Lane M: DL2000; lane 1: Chinese Spring; lane 2: Abbondanza; lane 3: Thinopyrum ponticum; lane 4: Thinopyrum intermedium; lane 5: tetraploid Pseudoroegneria spicata; lane 6: diploid Pseudoroegneria spicata; lane 7: Thinopyrum bessarabicum; lane 8: Thinopyrum elongatum; lane 9-15: wheat- Th. intermedium disomic addition lines (DALs), DA1St, DA2St; DA3St; DA4St; DA5St; DA6St; DA7St; lane 16: ES-9 (a and b), ES-10 (c and d); lane 17: ES-23 ( $a$ and b), ES-24 (c and d). 


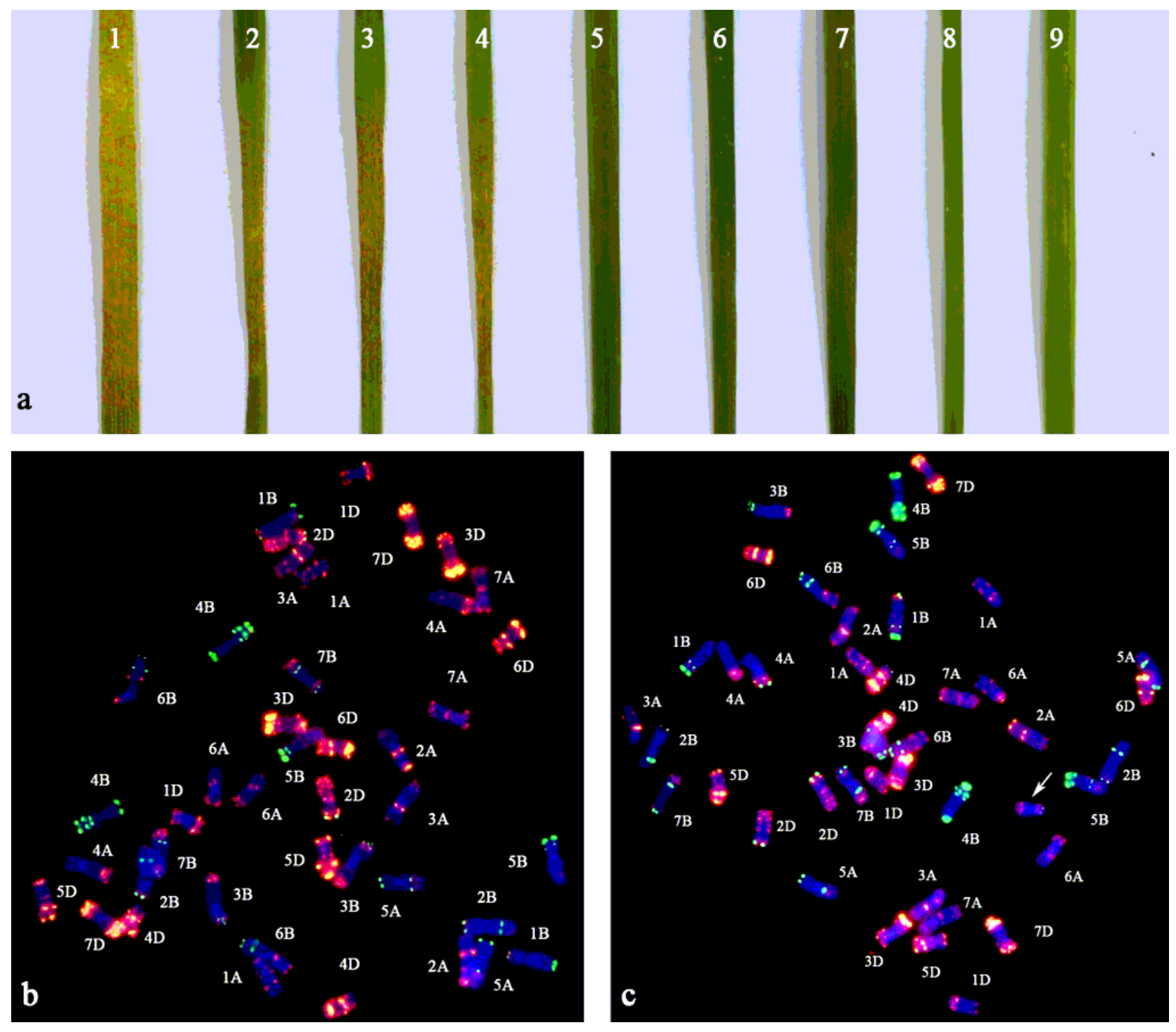

\section{Figure 7}

Stripe rust resistance evaluation and FISH analysis in BC1F2 individuals of ES-24 and Huixianhong. a Reactions to inoculation with the Pst race CYR32 of the BC1F2 individuals at the seedling stage; b FISH patterns of susceptible BC1F2 individuals; c FISH patterns of resistant BC1F2 individuals. (1) Huixianhong; (2)-(4) susceptible BC1F2 individuals; (5)-(7) resistant BC1F2 individuals; (8) Zhong4; (9) ES-24. The arrow indicates the chromosome 3St of Th. intermedium. 

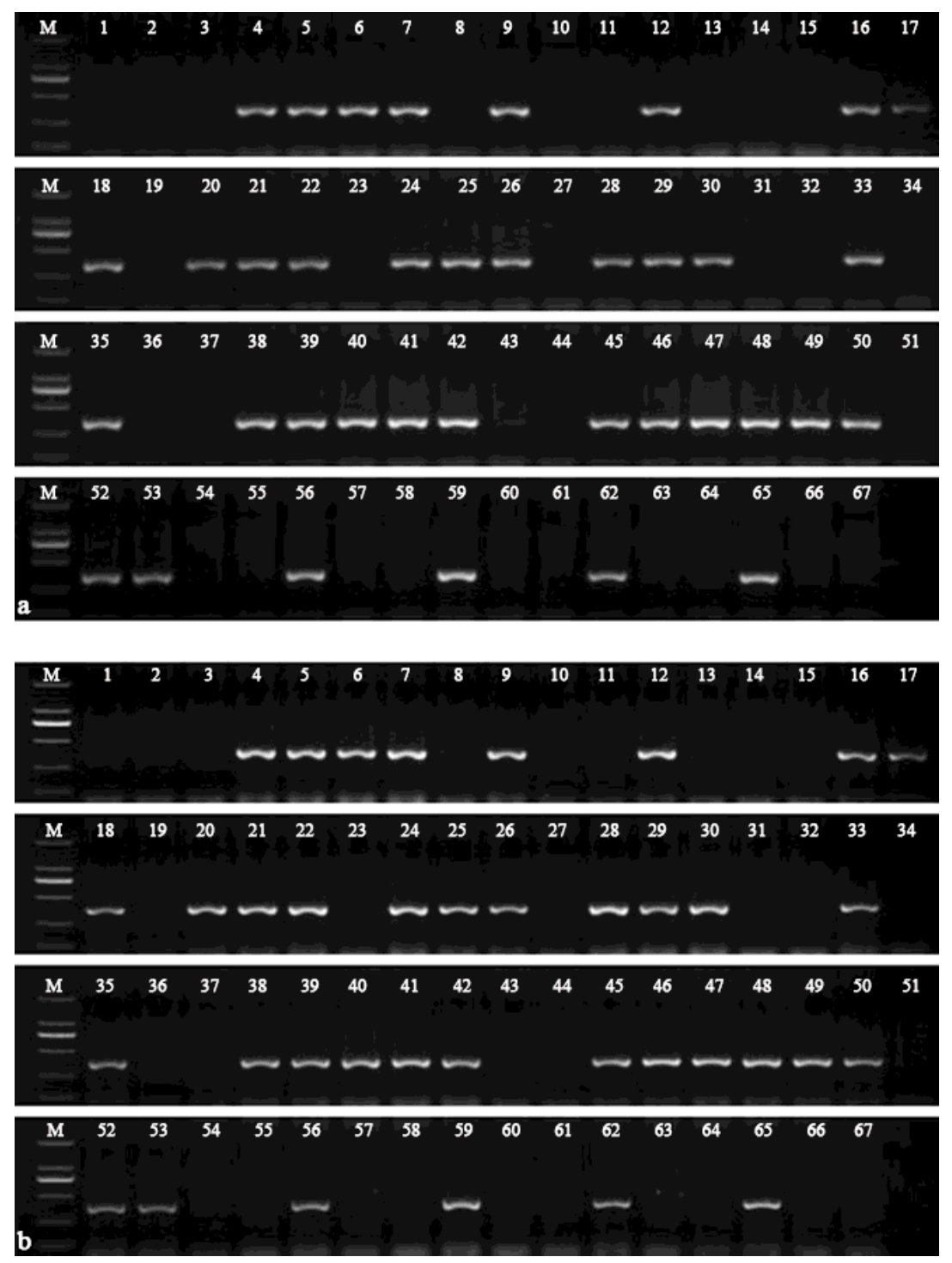

\section{Figure 8}

Utility of newly developed 3St-chromosome-specific markers in 60 BC1F2 individuals of ES-24 and Huixianhong (HXH). a PTH-113; b PTH-135. Lane M: DL2000; lane 1: Chinese Spring; lane 2: Abbondanza; lane 3: HXH; lane 4: Xiaoyan784 (wheat- Th. ponticum partial amphiploid with stripe rust); lane 5: Zhong4 (wheat- Th. intermedium partial amphiploid with stripe rust); lane 6: ES-10; lane 7:ES-24; lane 8-67: 60 BC1F2 individuals. 